\title{
SEPARATA
}
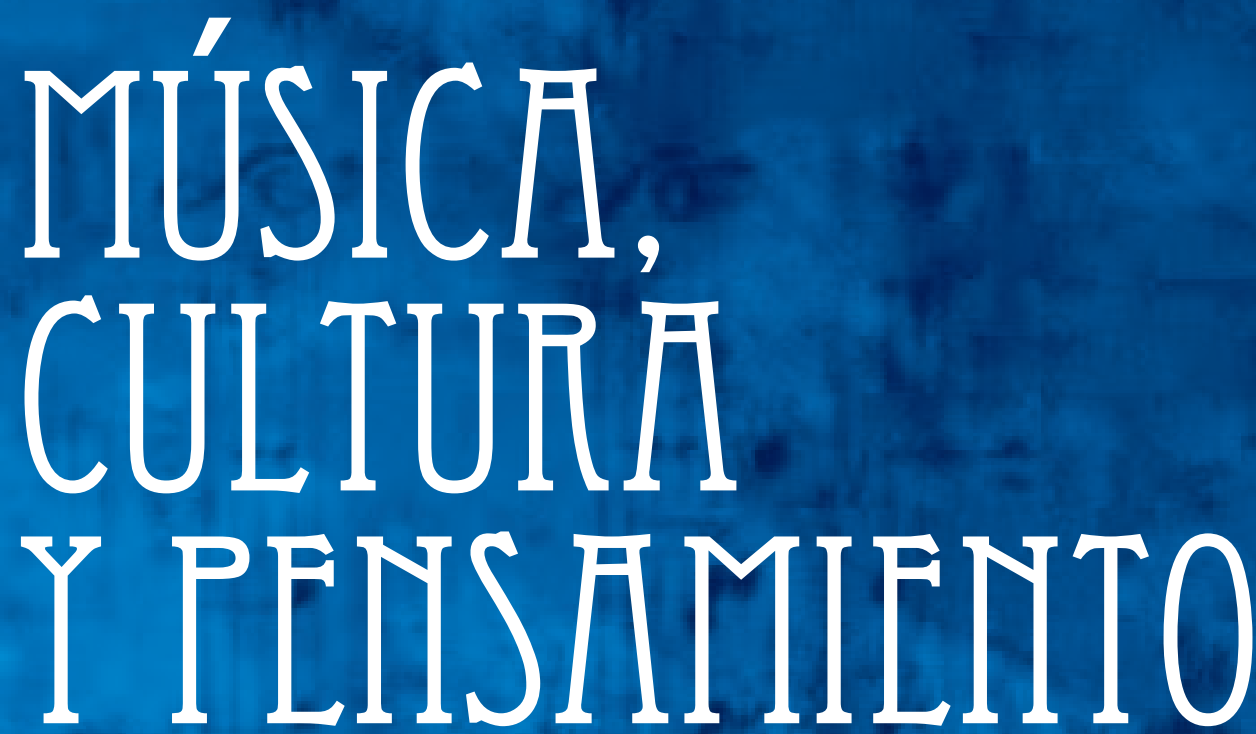

\section{Maruja Hinestrosa}

\section{Fantasía sobre Aires Colombianos}

Concierto para piano y orquesta Arreglo: Julián Augusto Castro Gaviria 
Separata Fantasía sobre Aires Colombianos

Música, Cultura y Pensamiento, vol. 8 , núm. 8 Revista de la Facultad de Educación y Artes.

(c) Fondo Editorial Conservatorio del Tolima. 2019 Conservatorio del Tolima

36 páginas, partitura, $23 \times 30 \mathrm{~cm}$.

ISMN: 979-0-9005303-8-7

Prohibida la reproducción total o parcial de este material sin autorización escrita del Conservatorio del Tolima.
Diseño gráfico editorial, armada electrónica e impresión

Proceditor Ltda.

Calle $1 \mathrm{C}$ No. 27A - 01, piso 1, Santa Isabel

Tel.: 757 9200, proceditor@yahoo.es

Bogotá, D. C., Colombia 


\title{
Fantasía sobre aires colombianos Concierto para piano y orquesta - Arreglo: Julián Augusto Castro Gaviria
}

Julián Augusto Castro Gavirira, Anthony Sebastián Chunganá, Andrés Felipe Gómez

\section{Resumen}

Esta obra presenta la orquestación de tres principales obras de la compositora Maruja Hinestrosa, a través de la investigación de su vida y obra musical, al igual que sus referentes académicos y estilísticos, En este proceso de investigación- creación se abarcaron diferentes técnicas de orquestación e instrumentación, tratados de importantes académicos del siglo XX y distintas técnicas de ejecución instrumental, así como también un estudio de las principales técnicas orquestales empleadas por músicos arreglistas a obras icónicas de la música colombiana. Se seleccionó esta obra, ya que fue el sueño de la compositora Maruja Hinestrosa ver reflejado el bosquejo para piano que empezó en los años 50, en un concierto para piano acompañado de orquesta.

Palabras Claves: Orquestación, instrumentación, nacionalismo, fantasía

\begin{abstract}
This work presents the orchestration of three main works of the composer Maruja Hinestrosa, through the investigation of her life and musical work, as well as her academic and stylistic references. In this process of investigation-creation, different techniques of orchestration and instrumentation were covered, treatises of important academics of the 20th century and different techniques of instrumental execution, as well as a study of the main orchestral techniques employed by musicians arranging iconic works of Colombian music. This work was selected because it was the dream of composer Maruja Hinestrosa to see the outline for piano that she began in the 1950s reflected in a concert for piano accompanied by an orchestra.
\end{abstract}

Keywords: Orchestration, instrumentation, nationalism, fantasy 


\section{Introducción}

ara la realización de este trabajo de orquestación, se estudiaron diferentes tratados de literatura musical universal (Berlioz, 1884; Rimsky-Korsakov, 1946; Carse, 1964; Piston, 1995) y se estudiaron las técnicas de instrumentación y orquestación que han sido aplicadas sobre el repertorio de música tradicional colombiana. Se tomó como referencia la orquestación ya realizada por el maestro Jaime Rosero de esta obra, que no fue bien aceptada dentro del ámbito musical por su ostentosidad orquestal y tímbrica y sus reelaboraciones de los pasajes ya establecidos, convirtiendo esta composición prácticamente en variaciones sobre la Fantasía para piano de Maruja Hinestrosa.

Se tomó como referencia sonora la interpretación de la obra a cargo del Maestro Luis Gabriel Mesa Martínez y la interpretación de la Compositora Maruja Hinestrosa. En el transcurso del proceso sobre el formato orquestal, se evidencian constantemente la dialéctica de las ideas primarias que se tenían anteriormente sobre los tres pentagramas. Se suman a este trabajo orquestal el estudio de los diferentes aires que contiene la obra como el bambuco, la guabina y el pasillo, para una buena interpretación estilística sobre todo en la parte de la percusión, que fue un trabajo casi aparte del primer proceso sobre la orquesta.

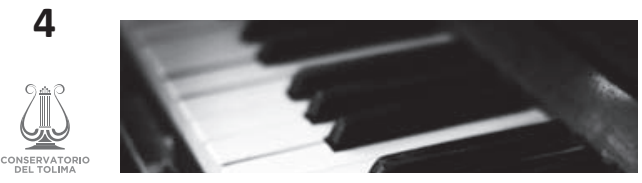


Fantasía sobre Aires Colombianos (Concierto para piano y orquesta)

Compositor: Maruja Hinestrosa

Orauestación: Julián Castro Gaviria

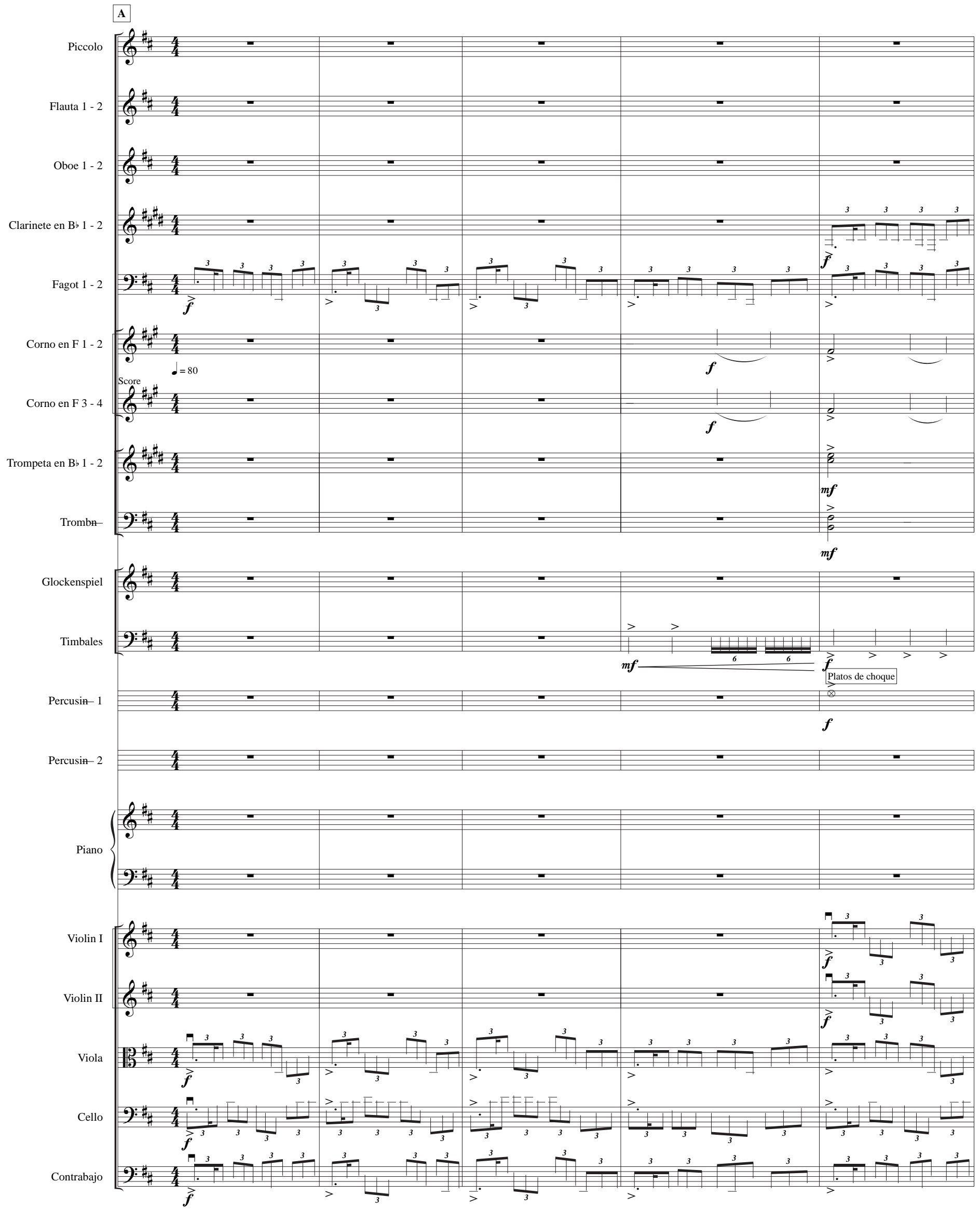




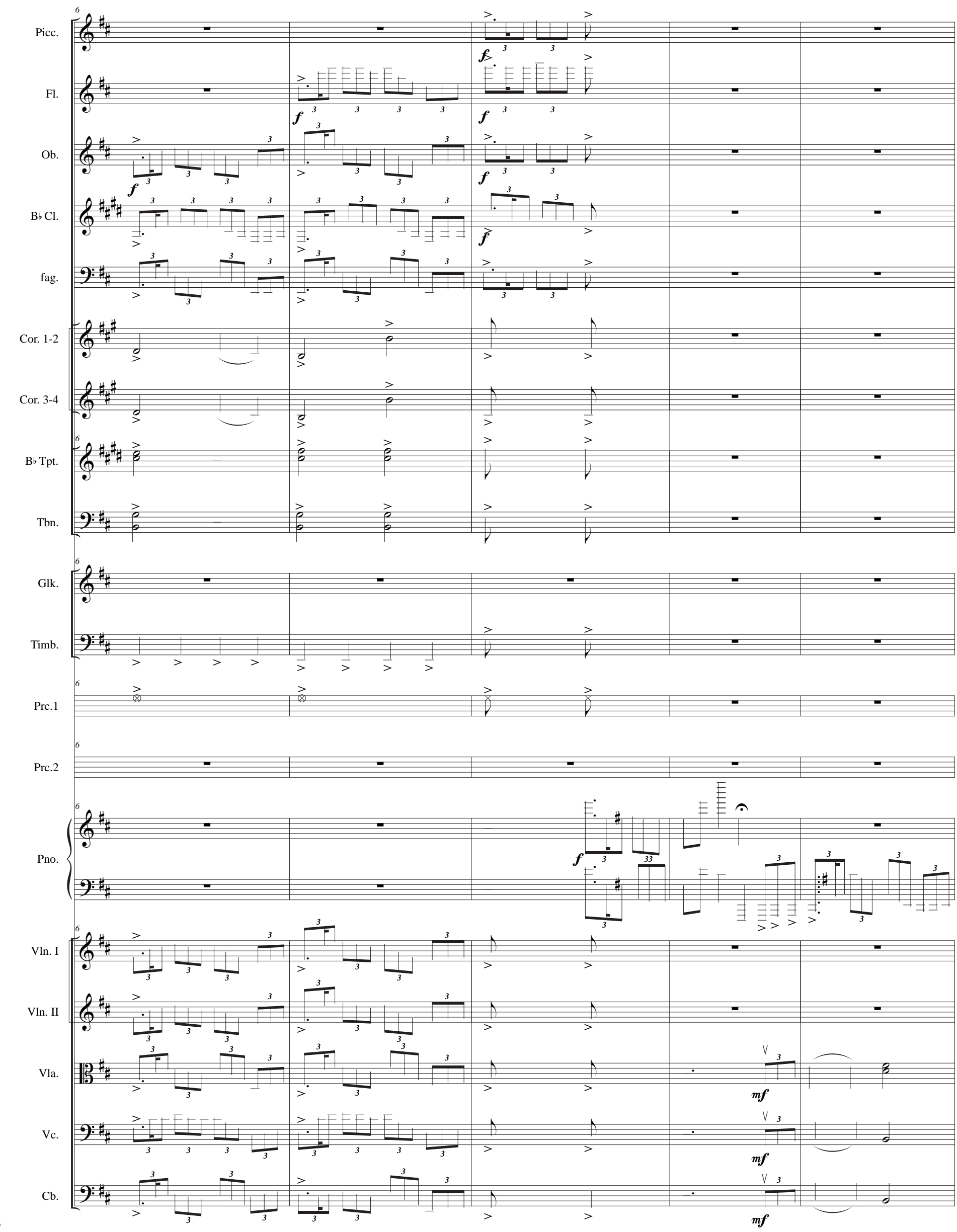



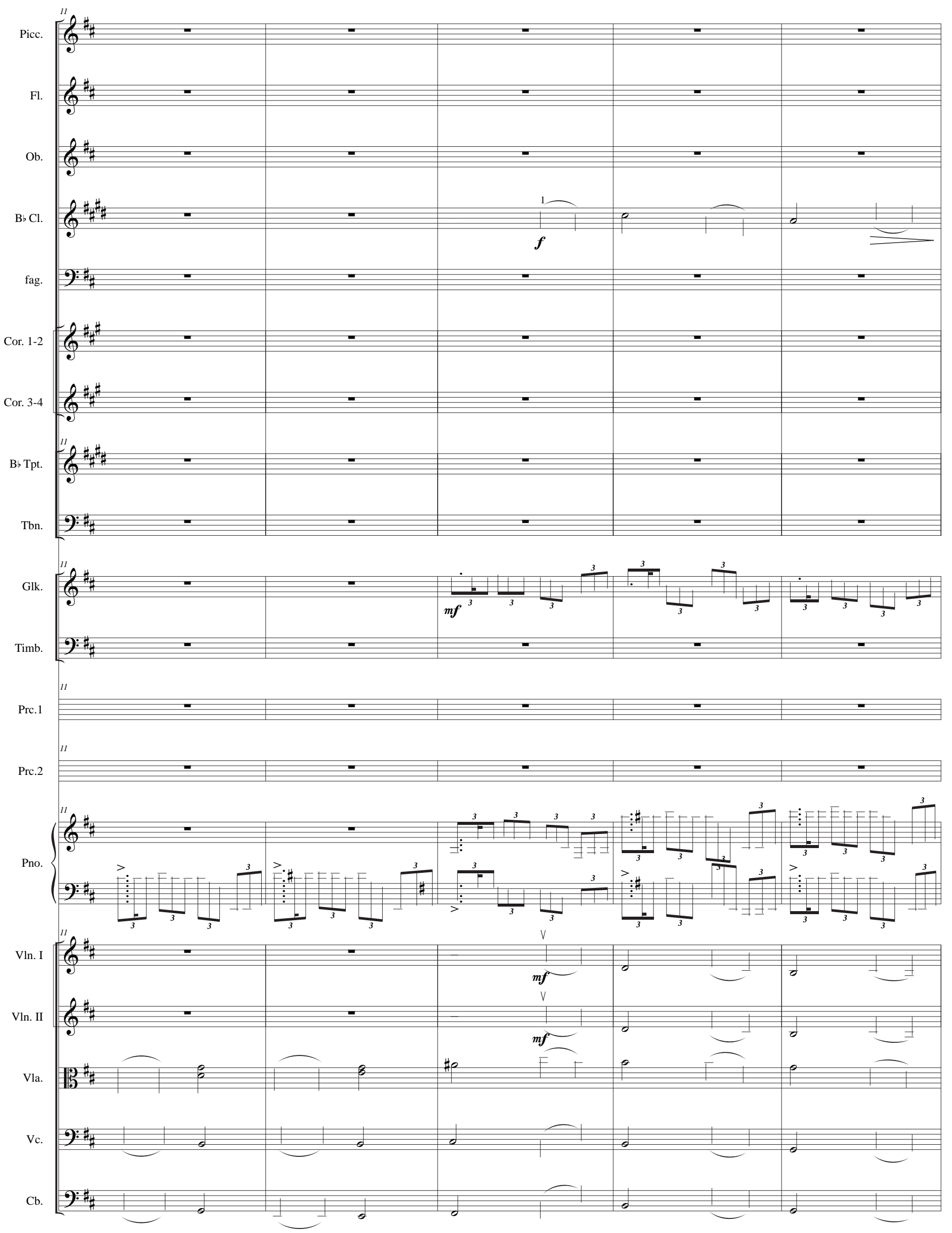


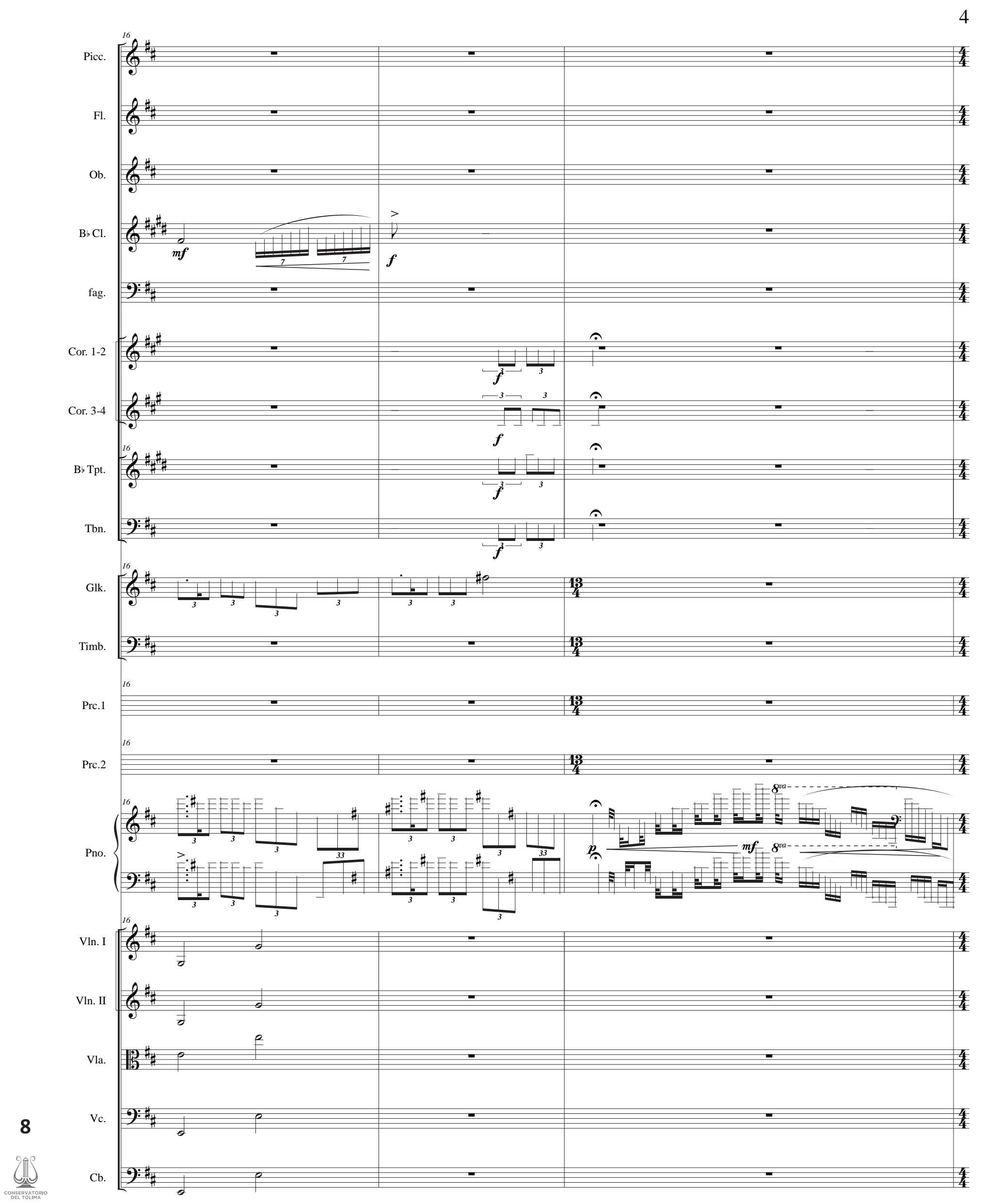



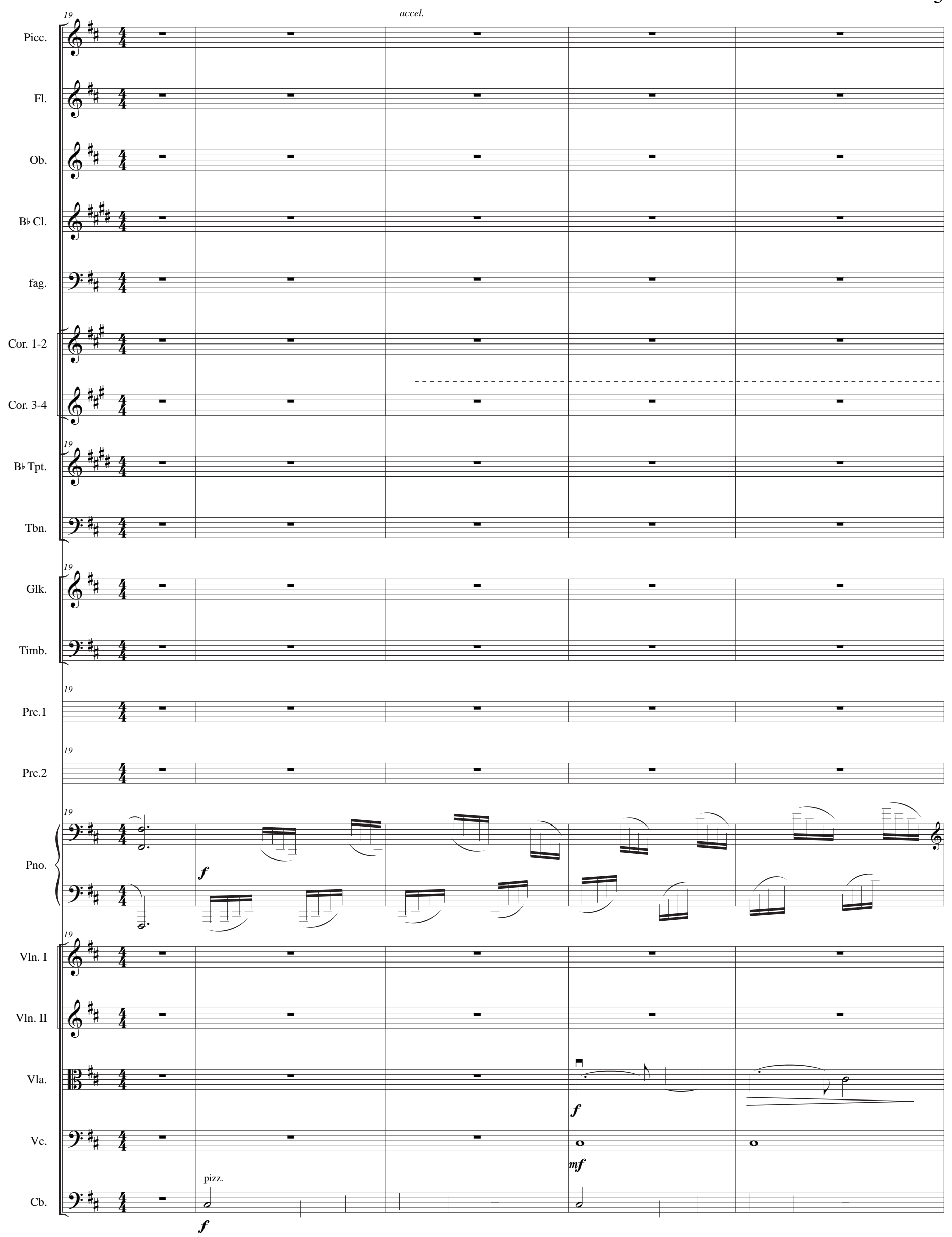

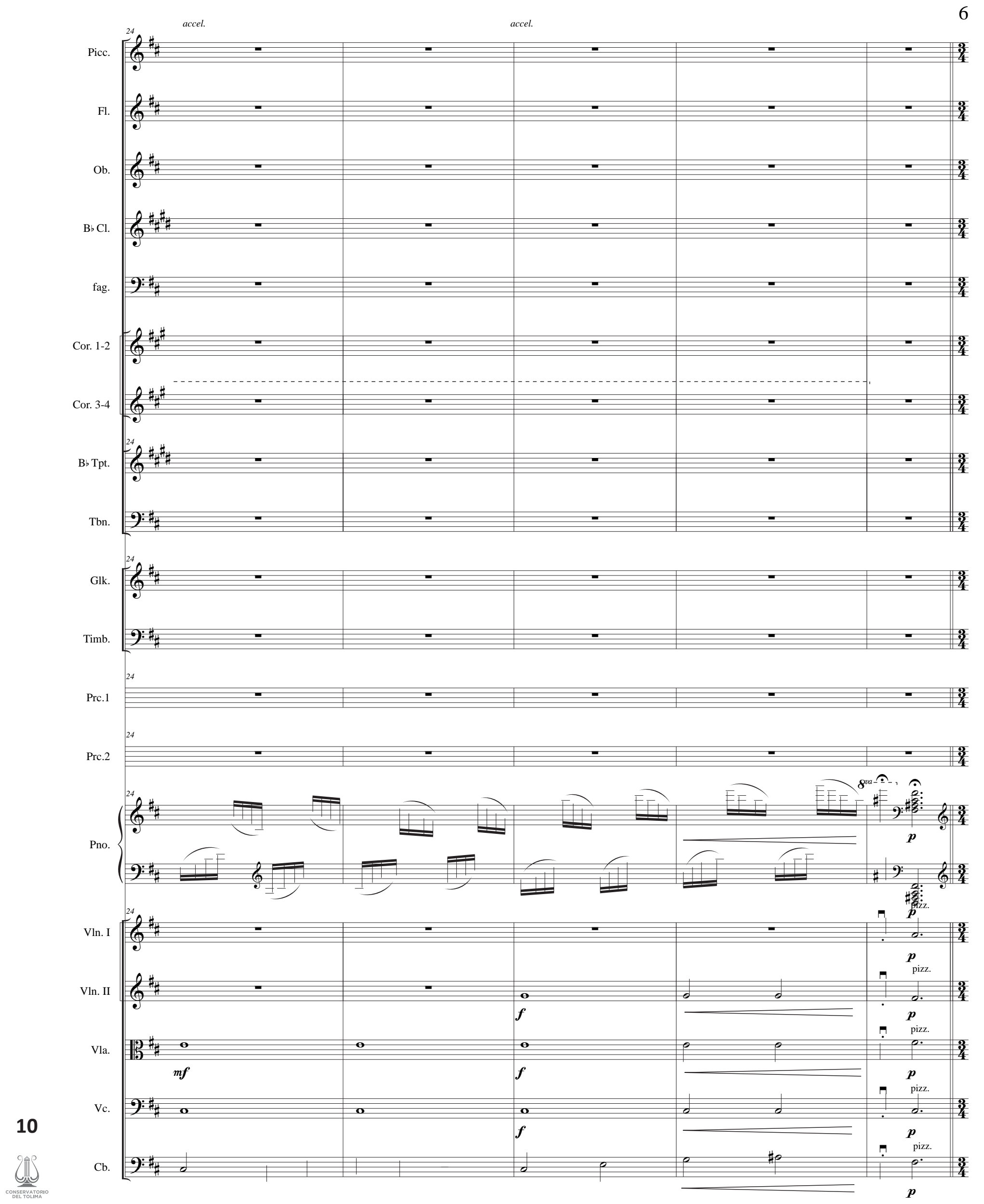


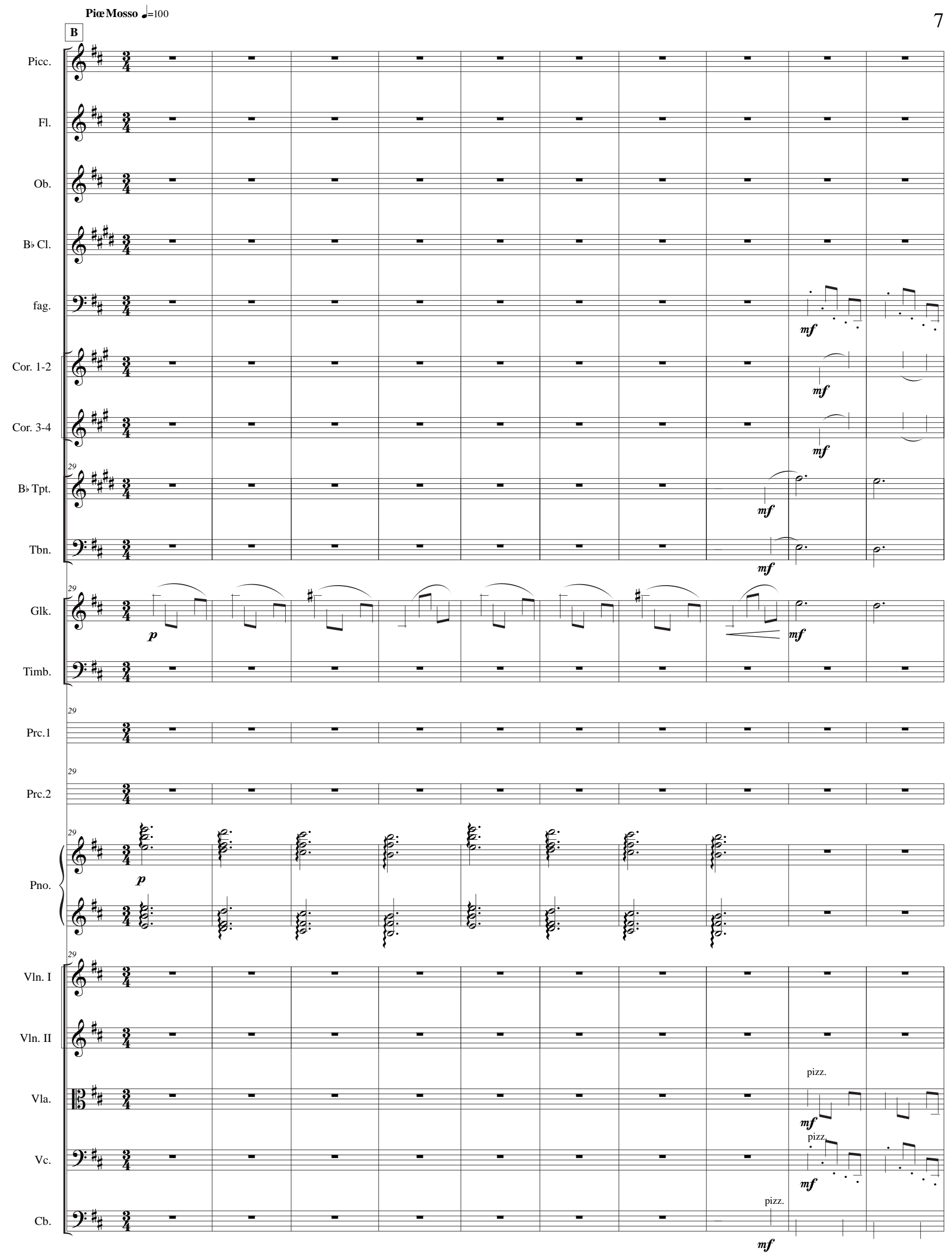



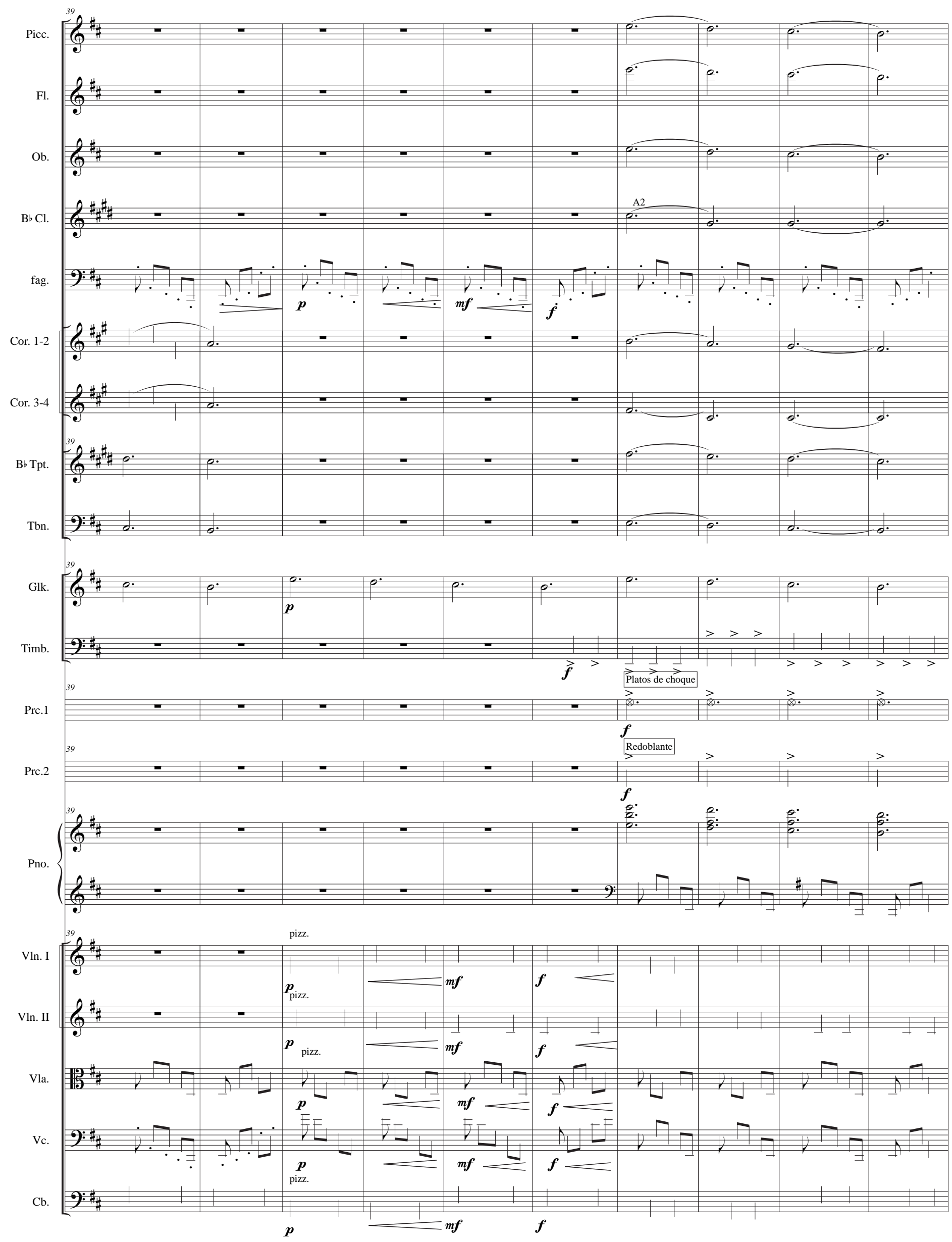
C
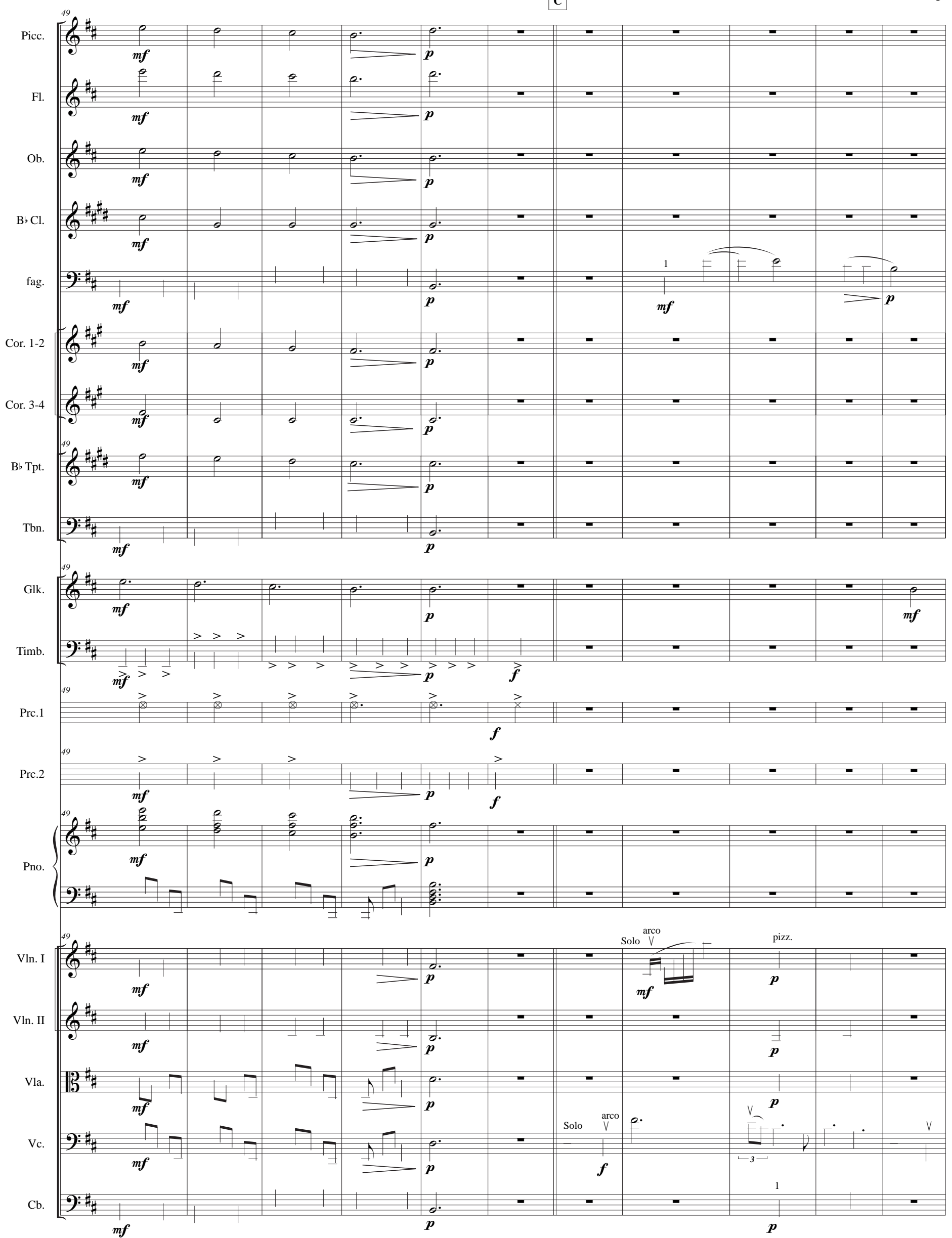

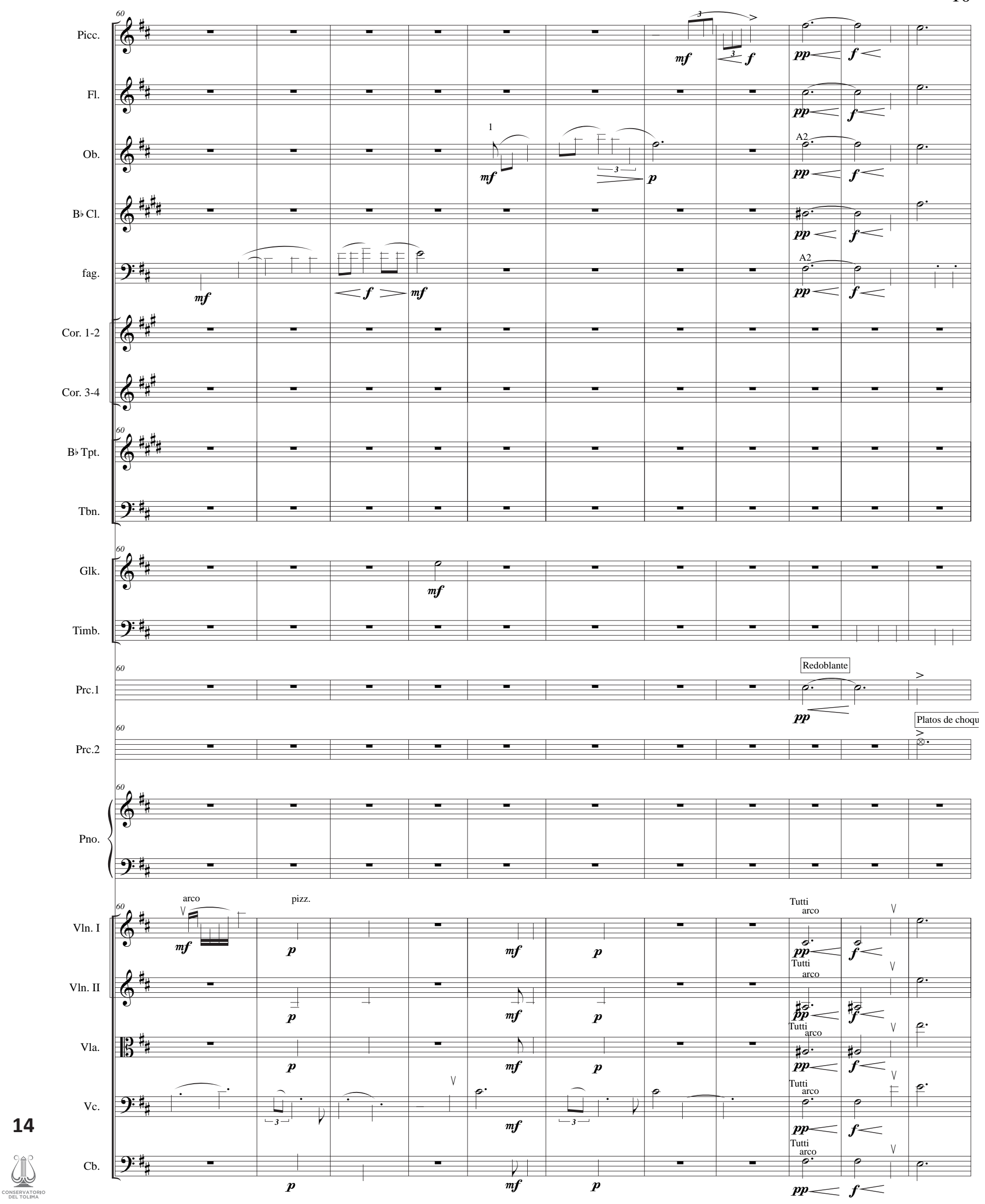

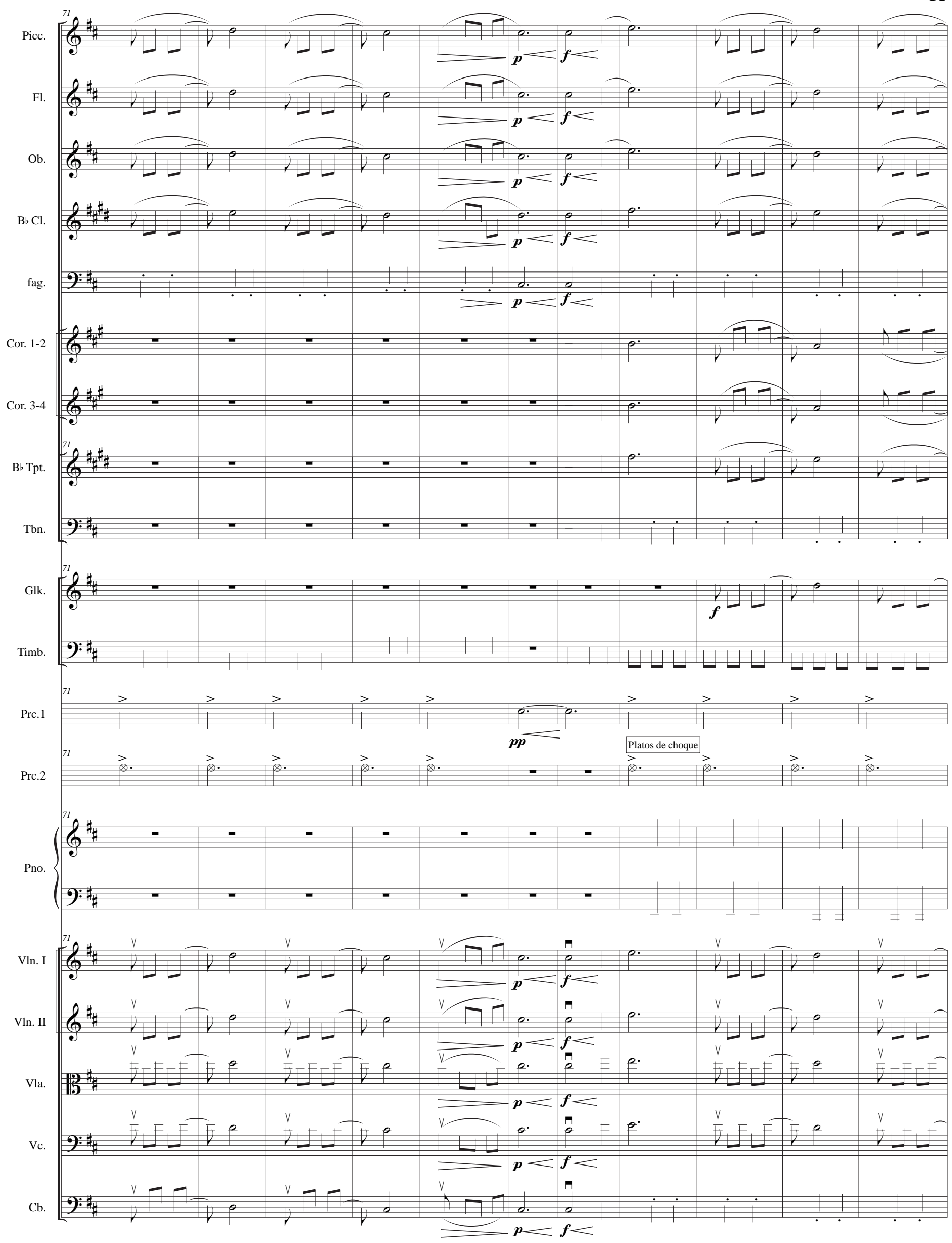

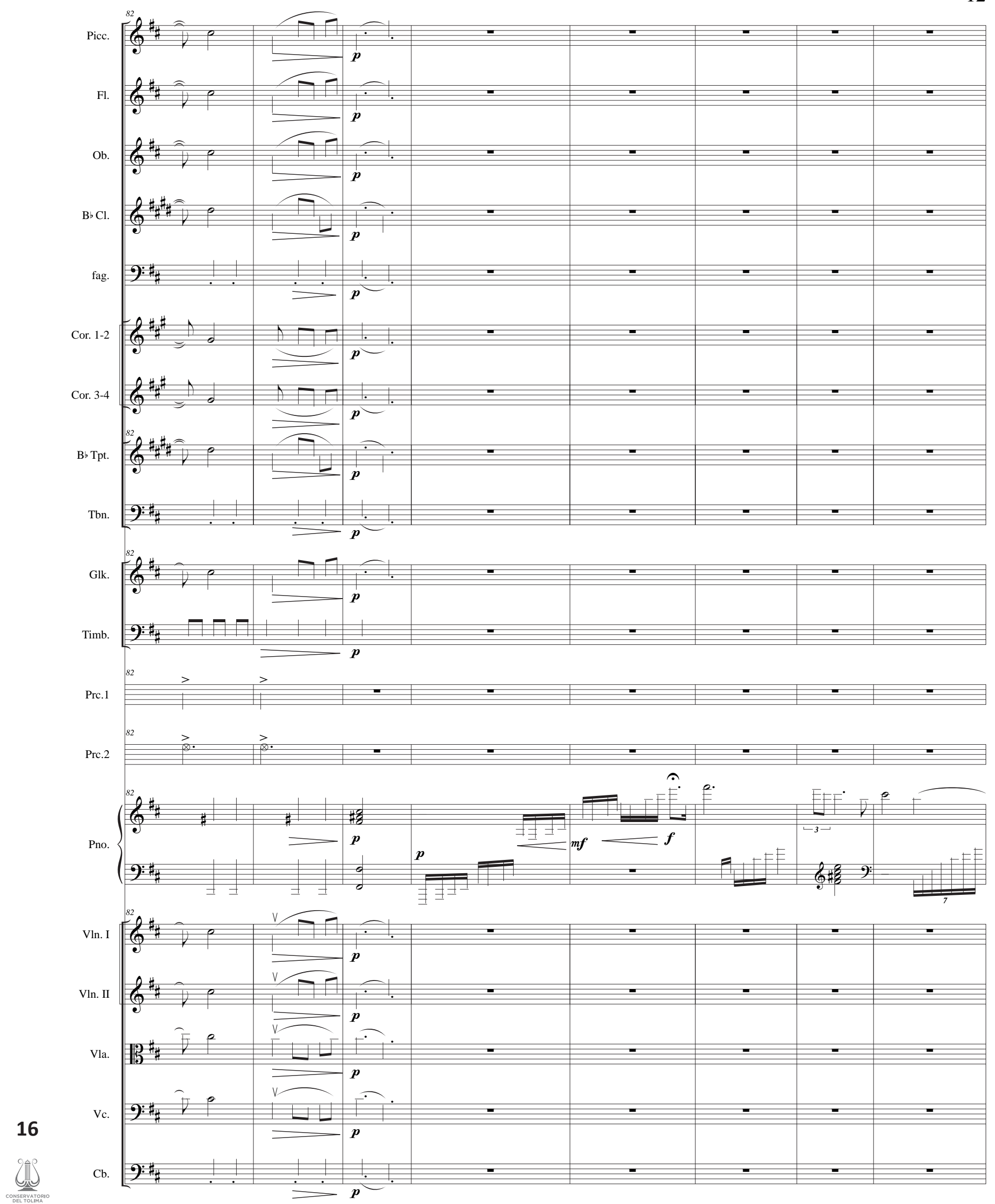

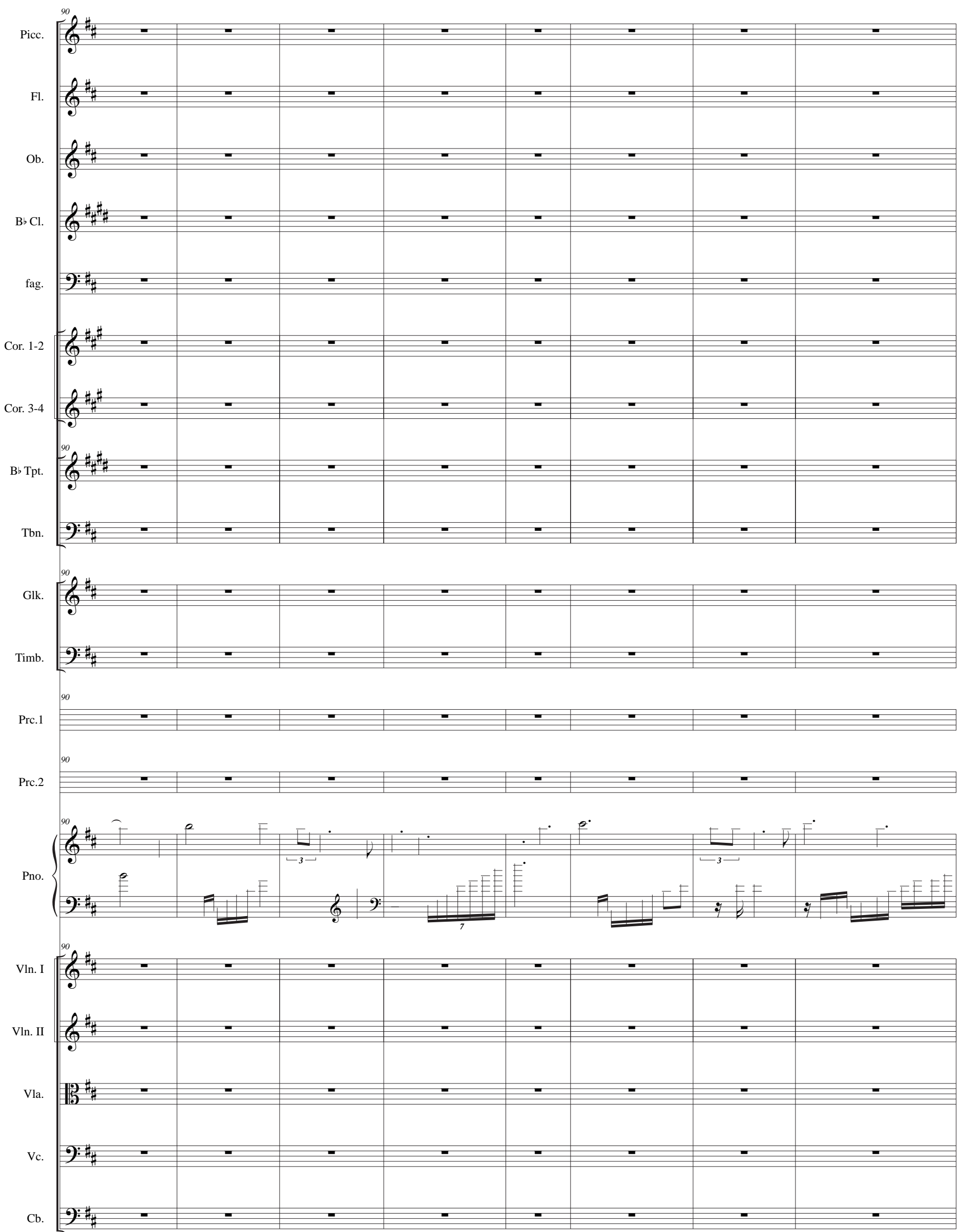

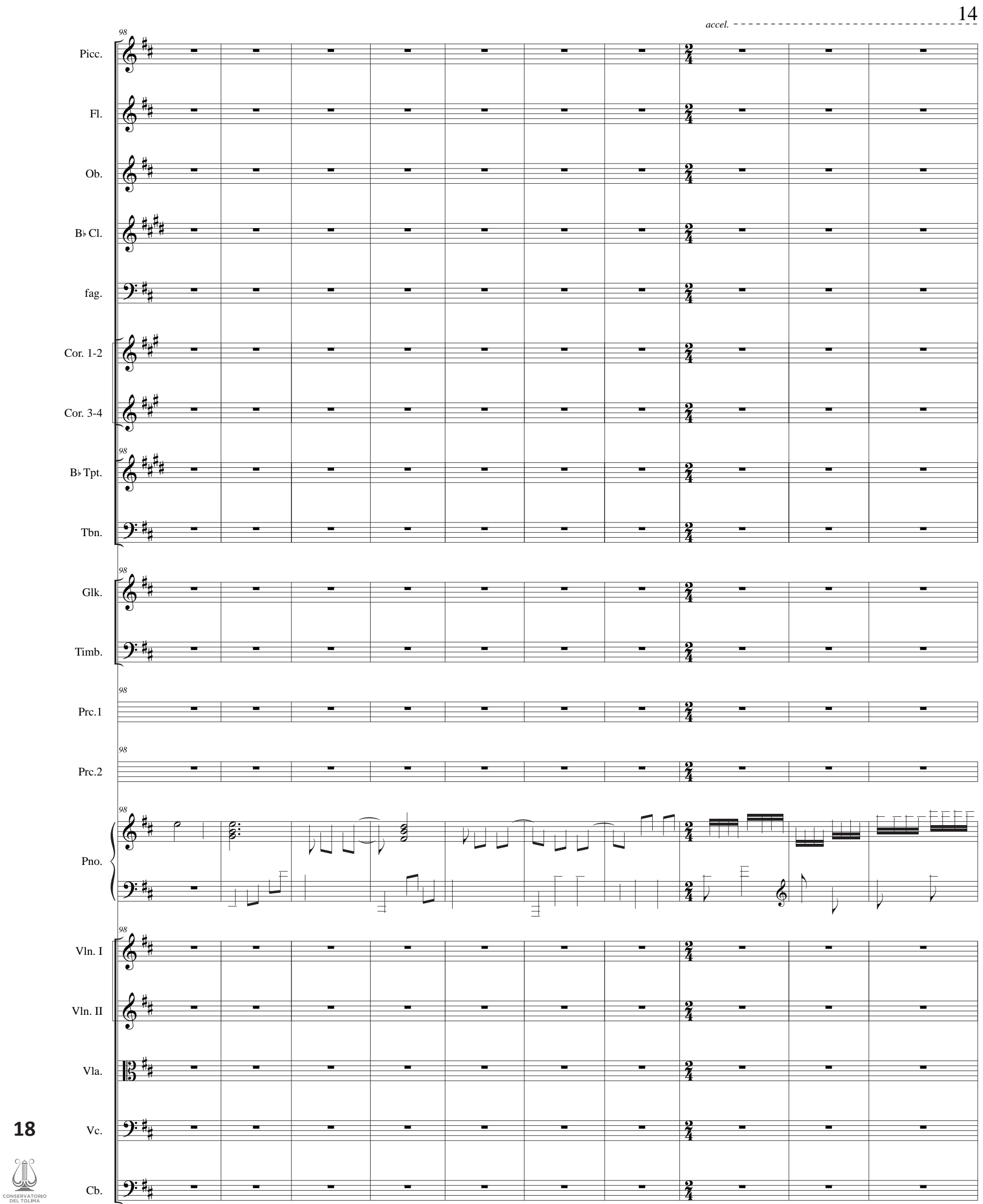

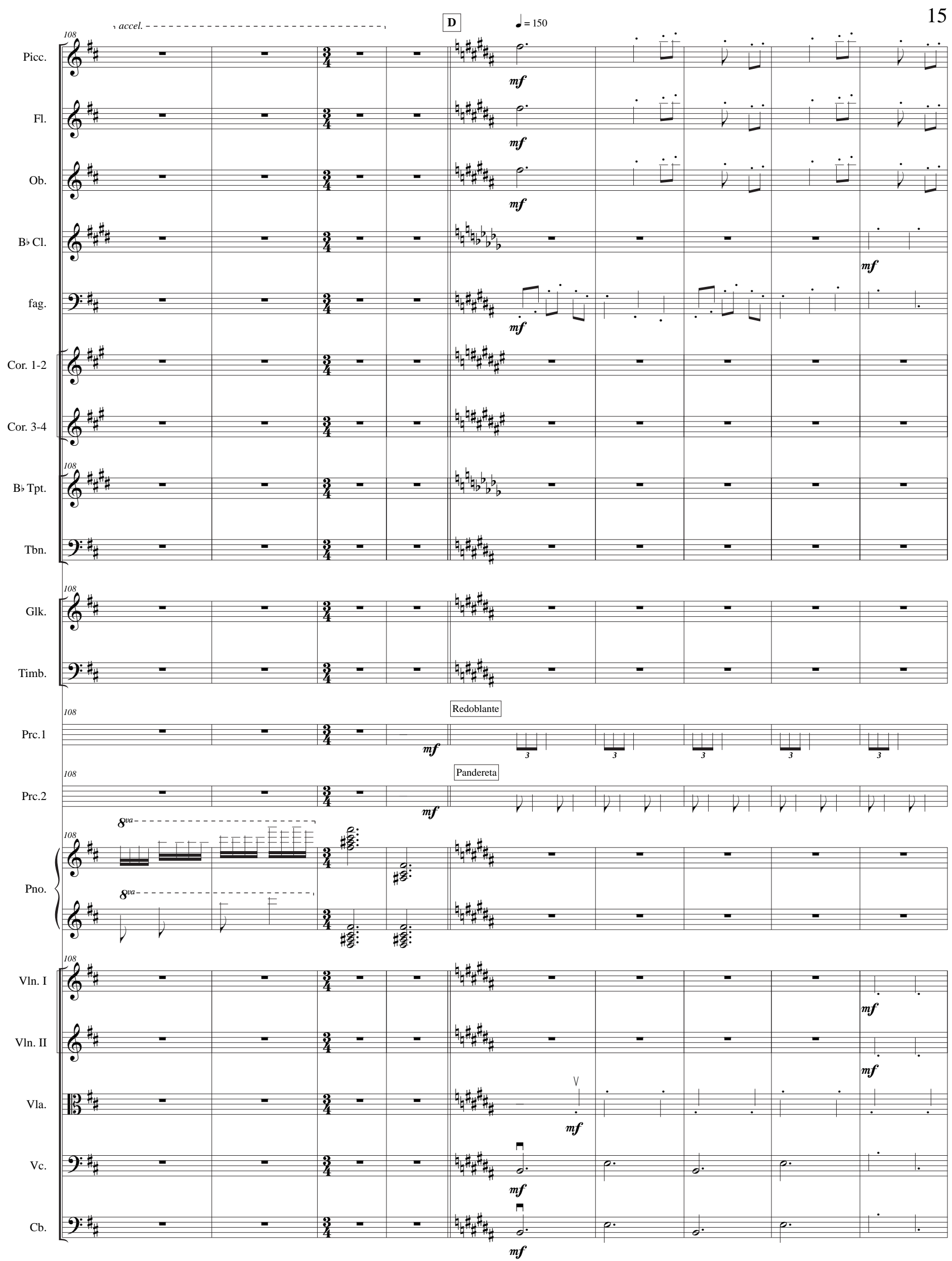

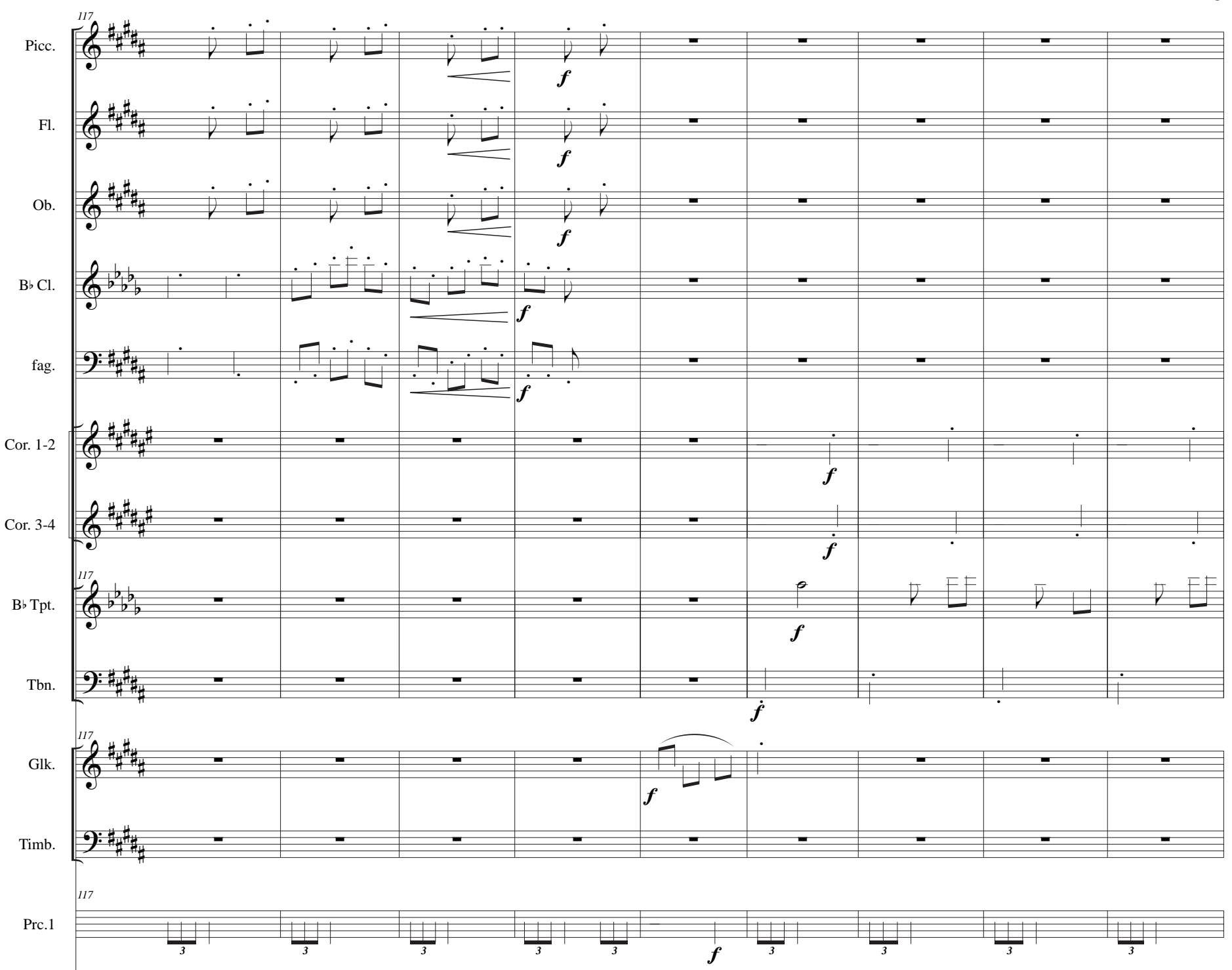

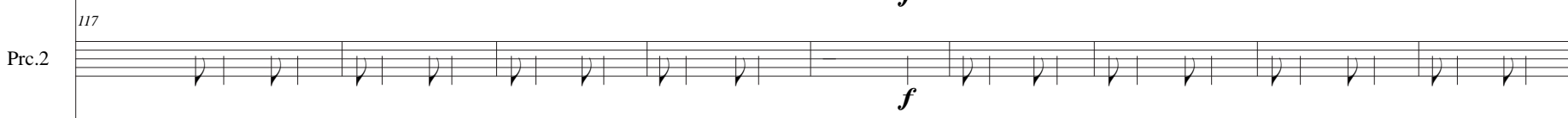
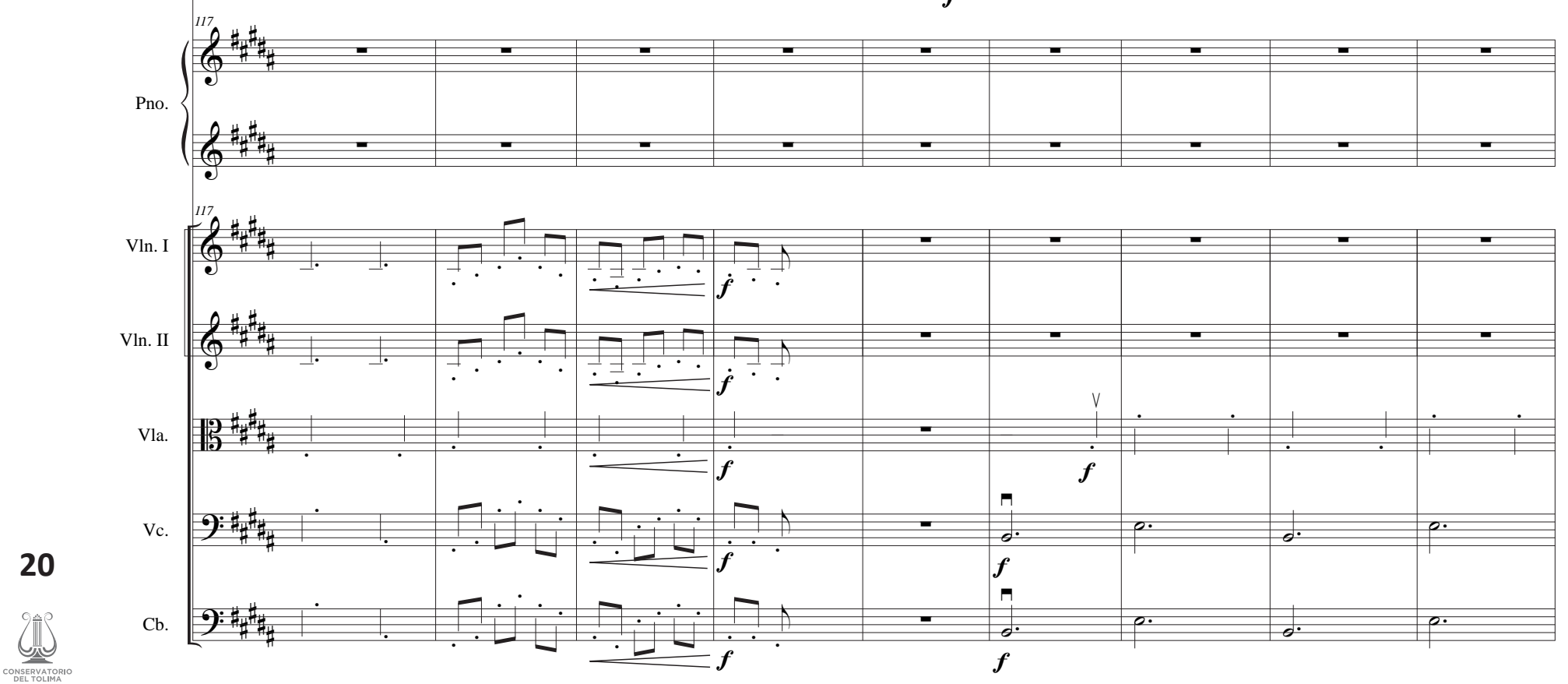

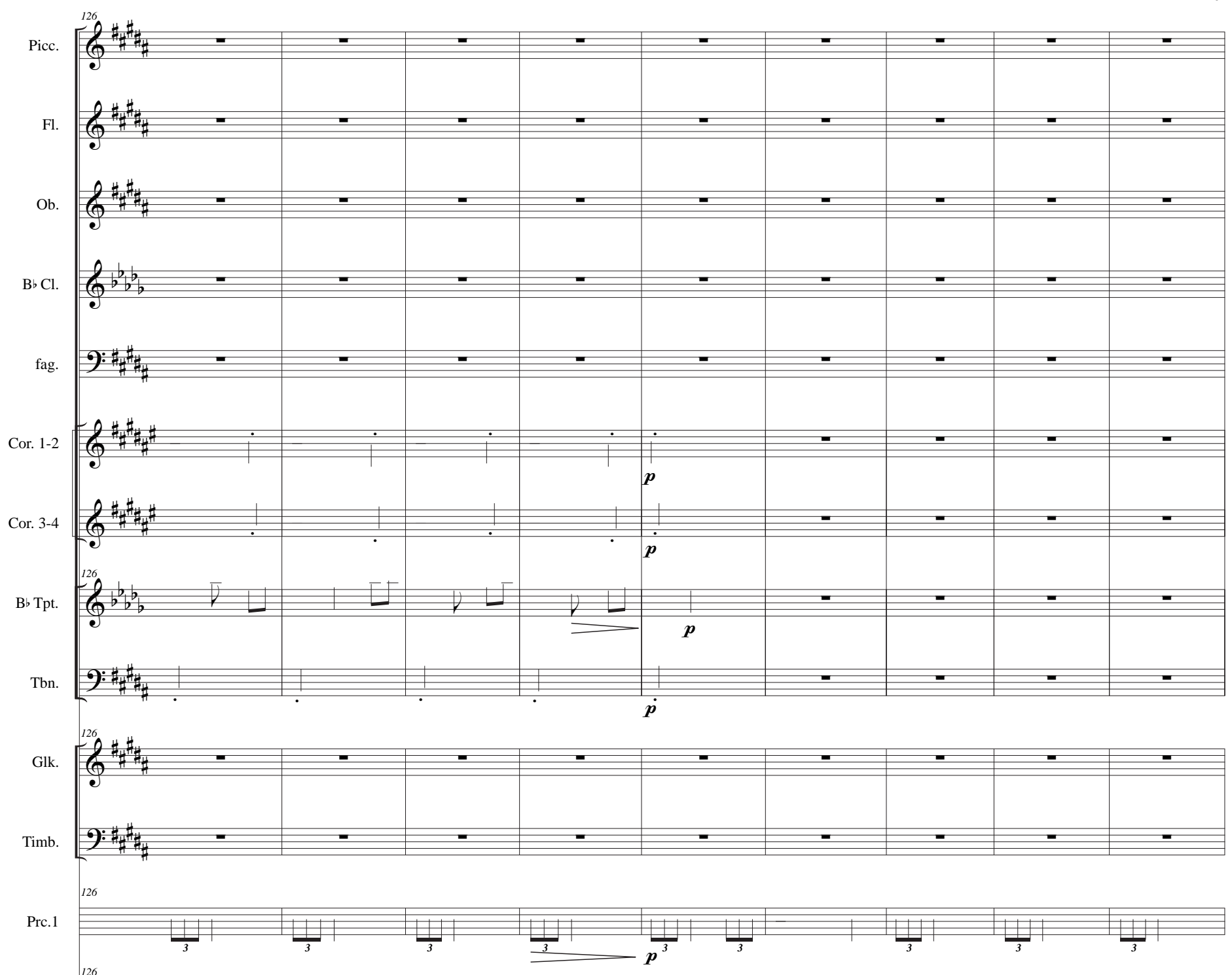

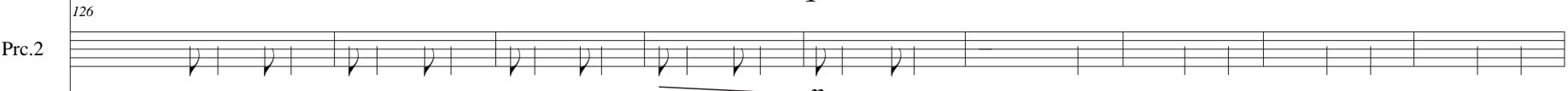
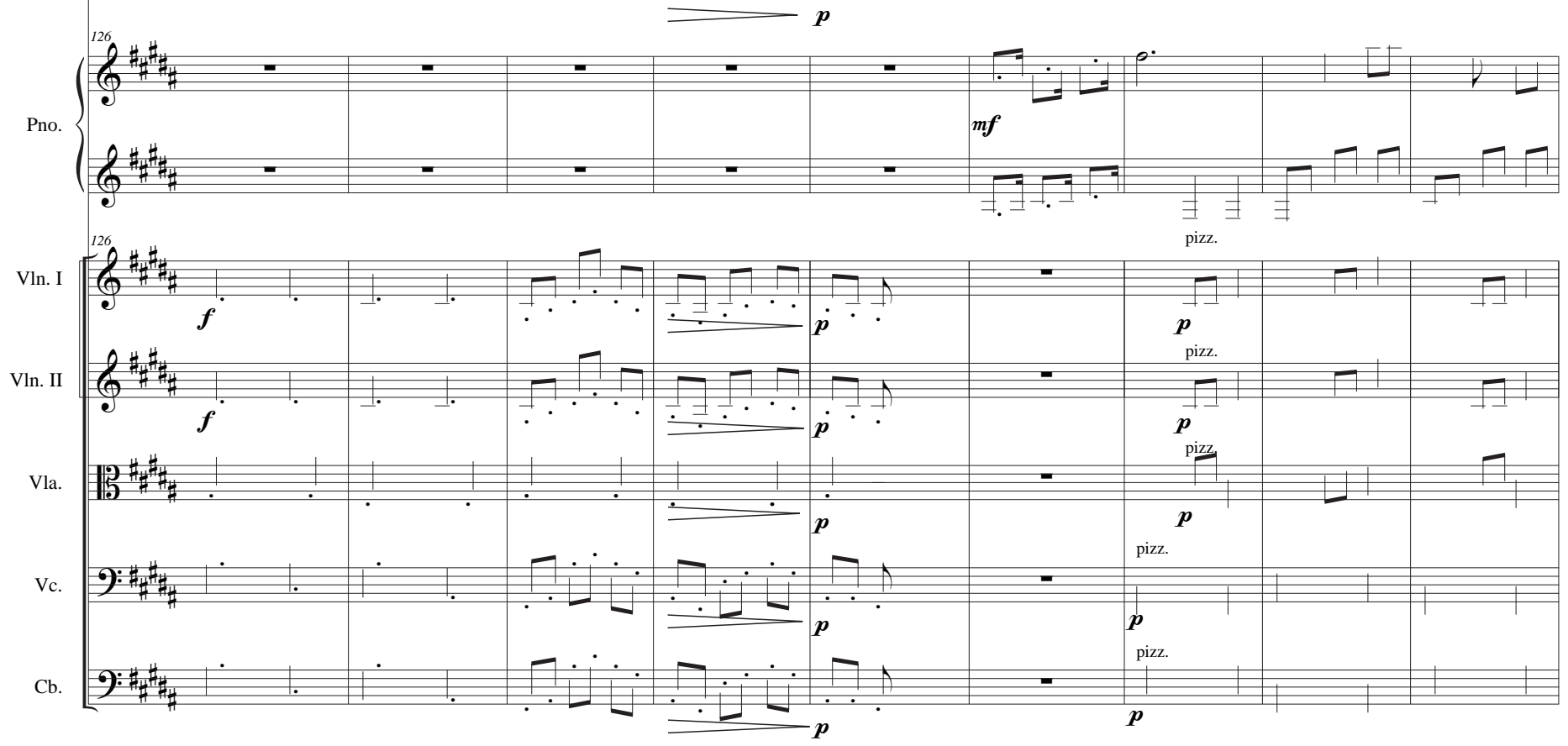

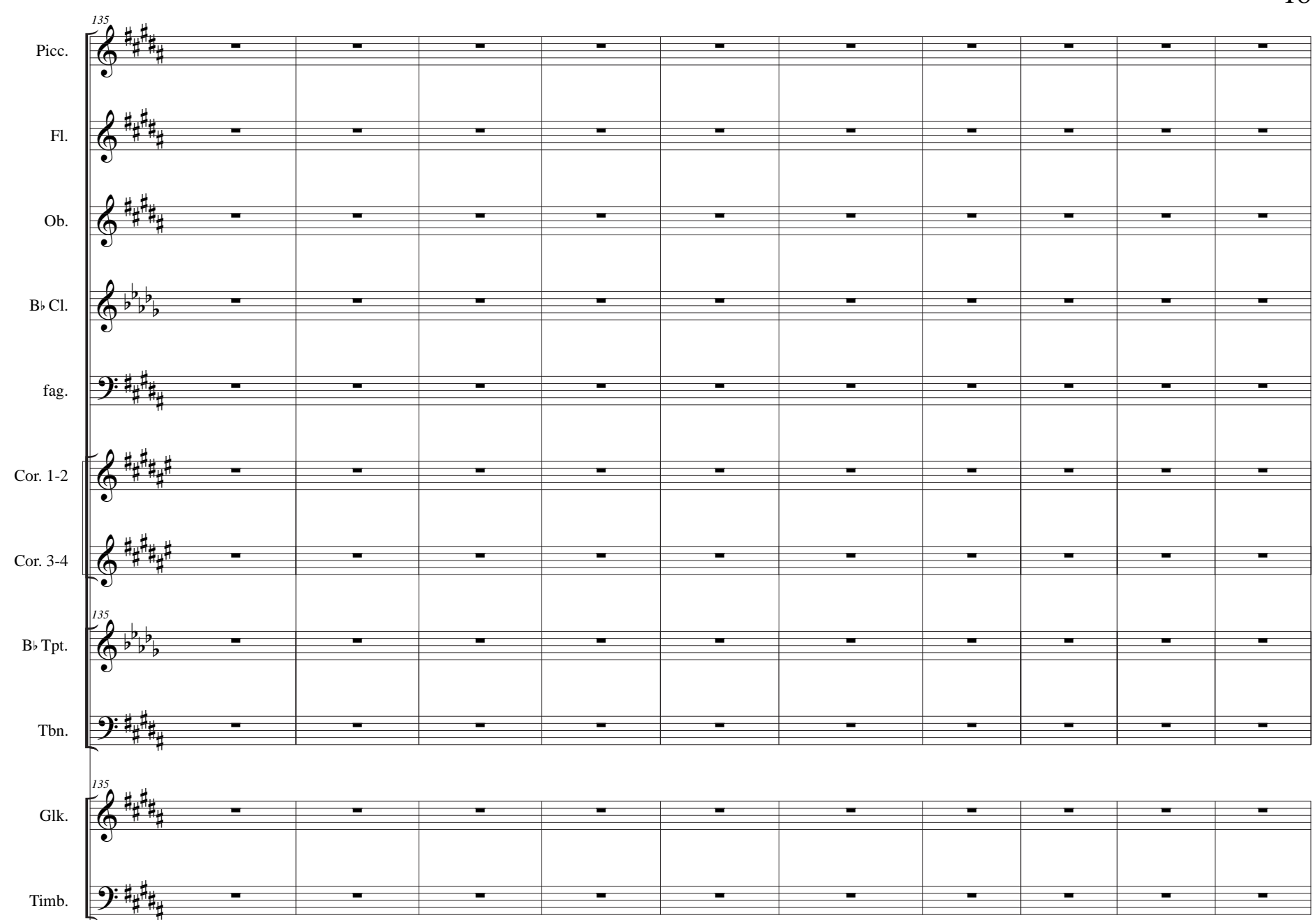

$\operatorname{Prc} 11$ 135 Prc.2 \cline { 2 - 2 }$^{135}$

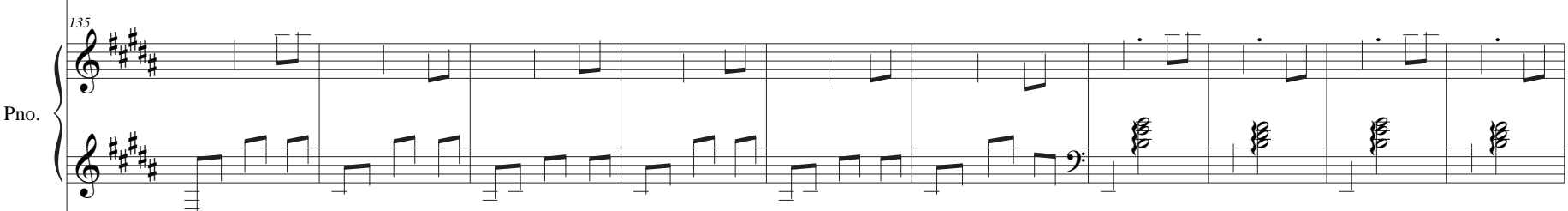
VIn.II 

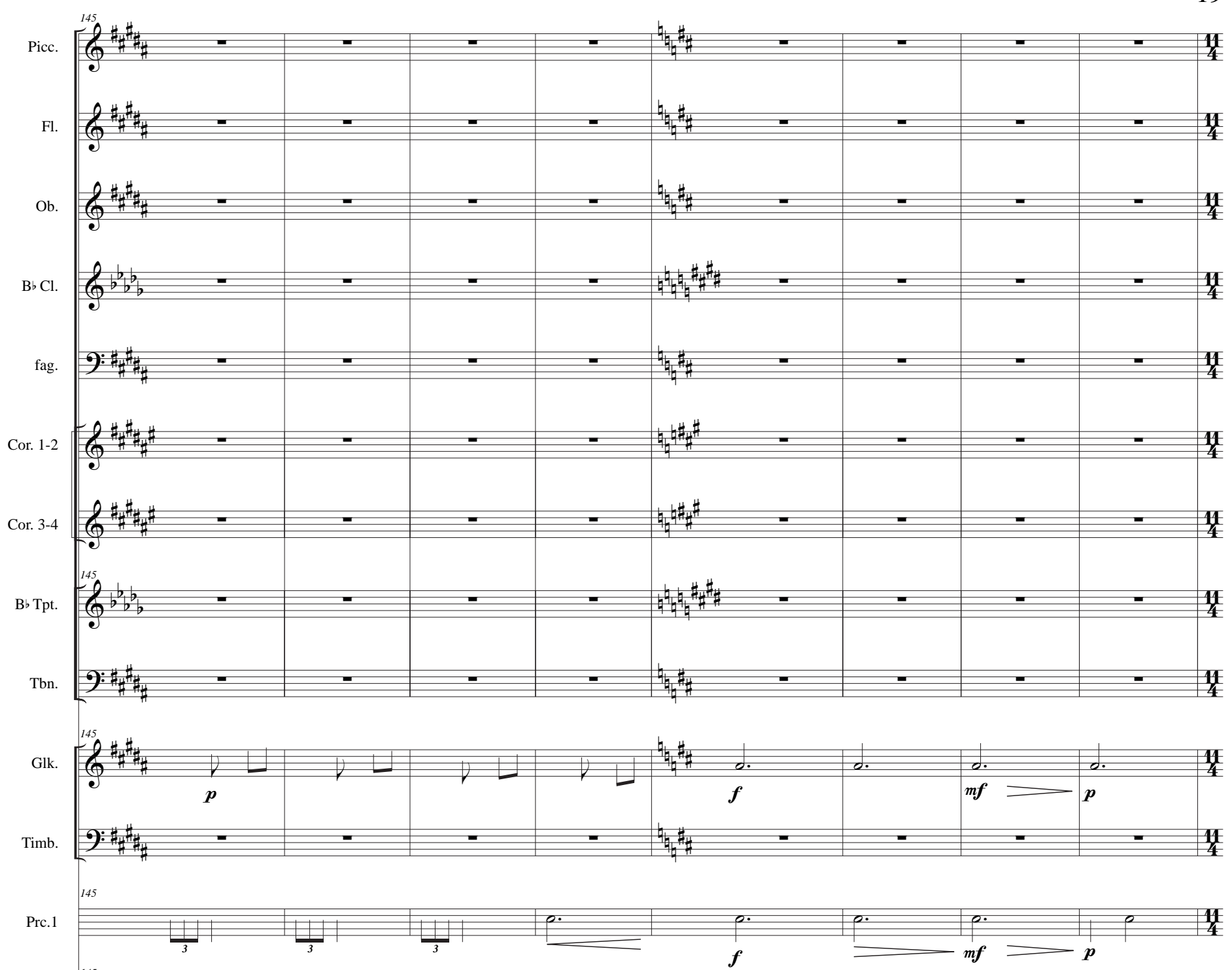

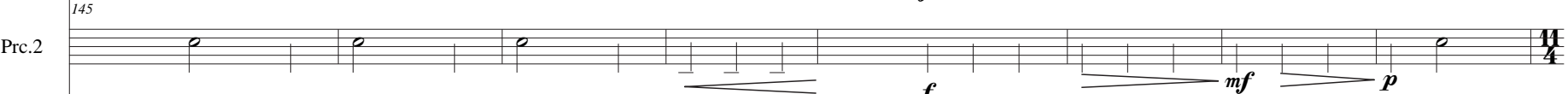

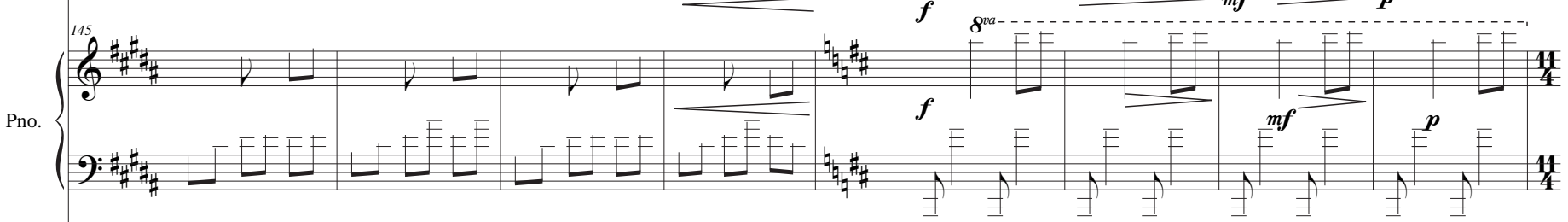

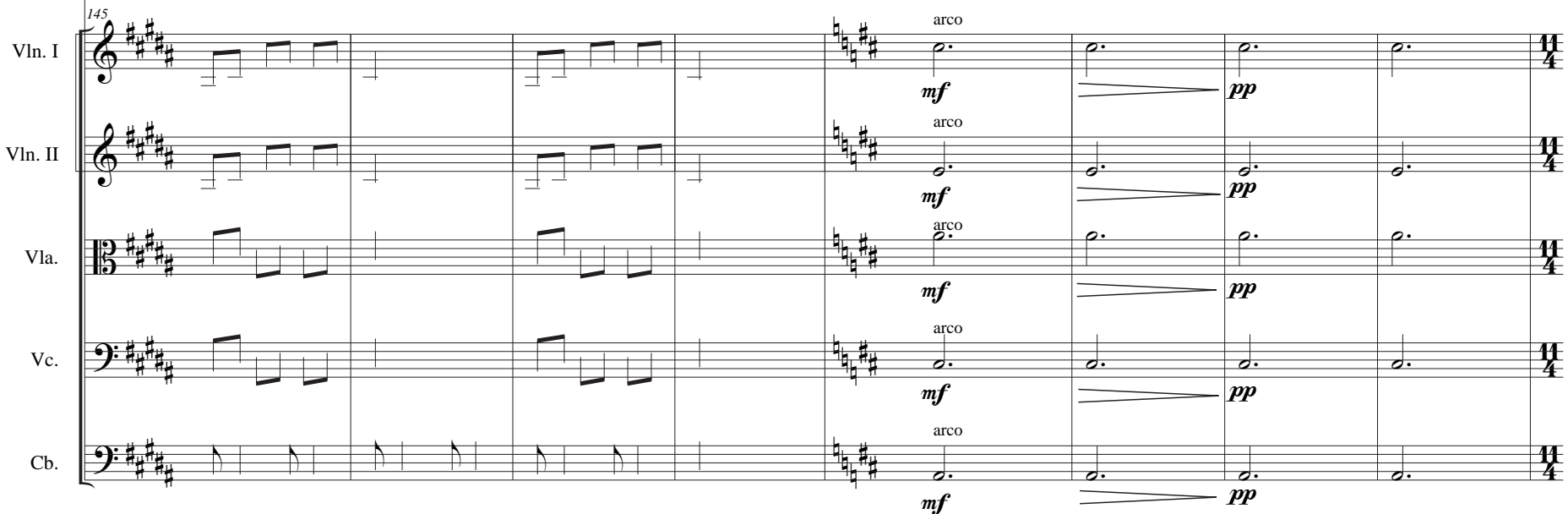




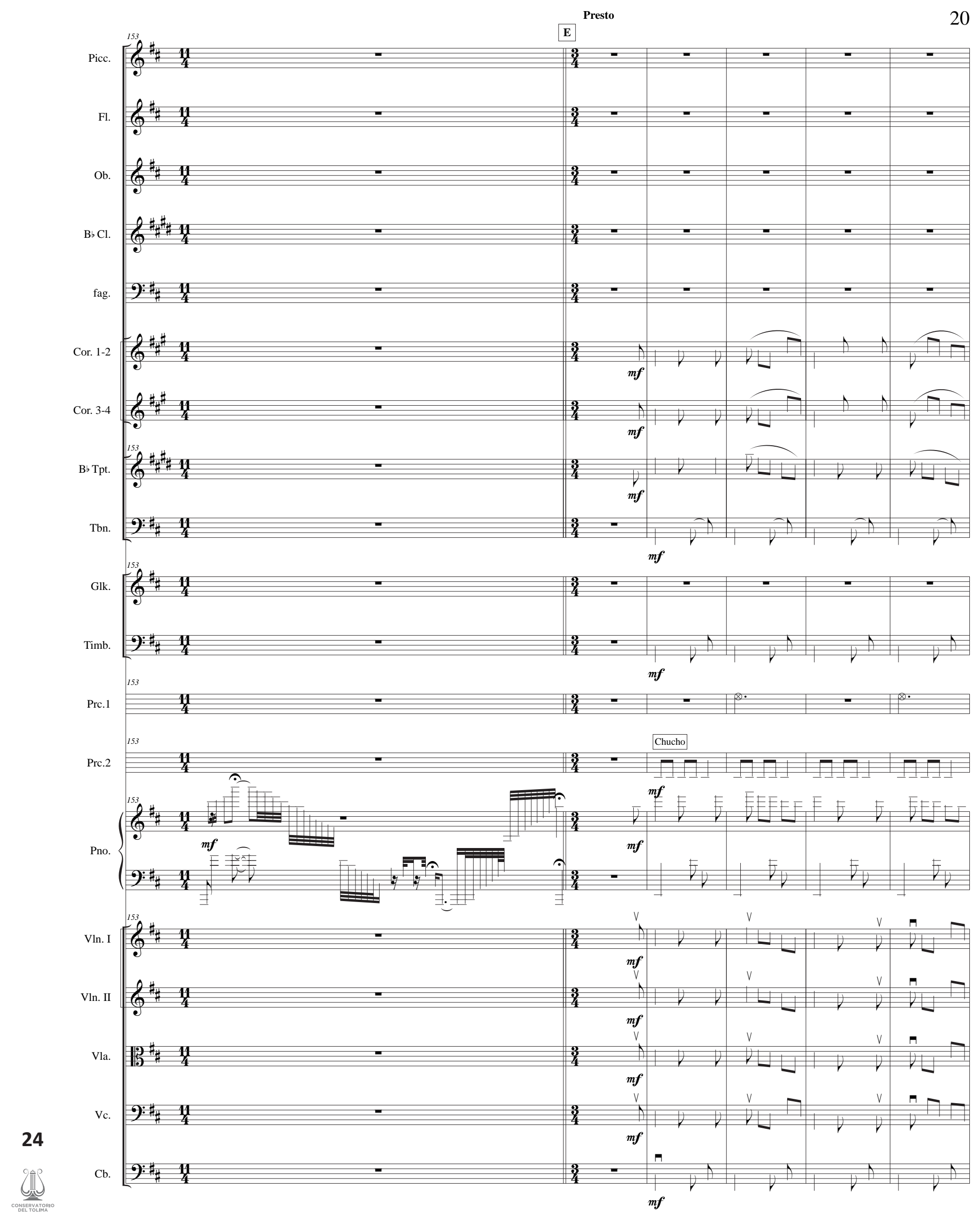



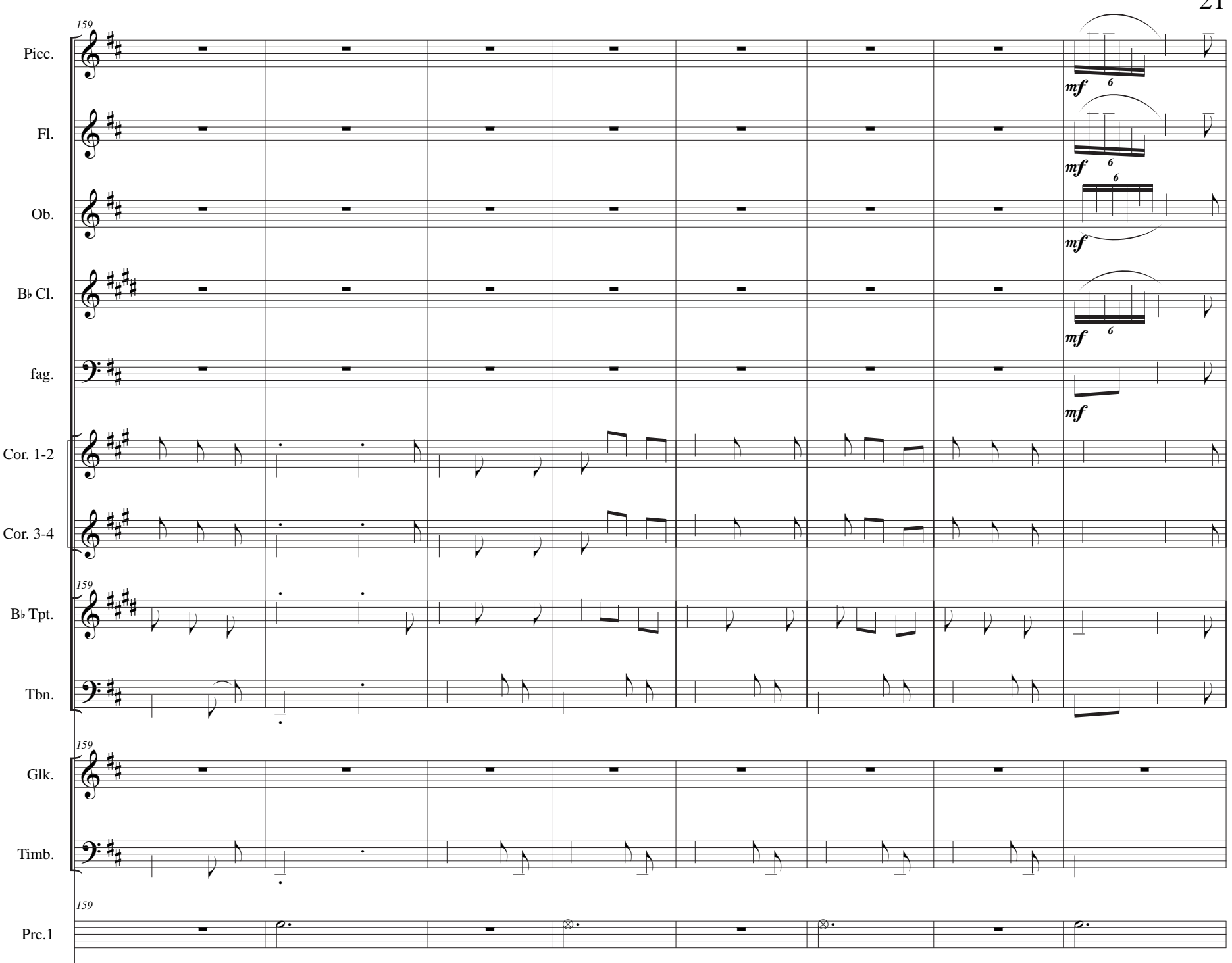

159
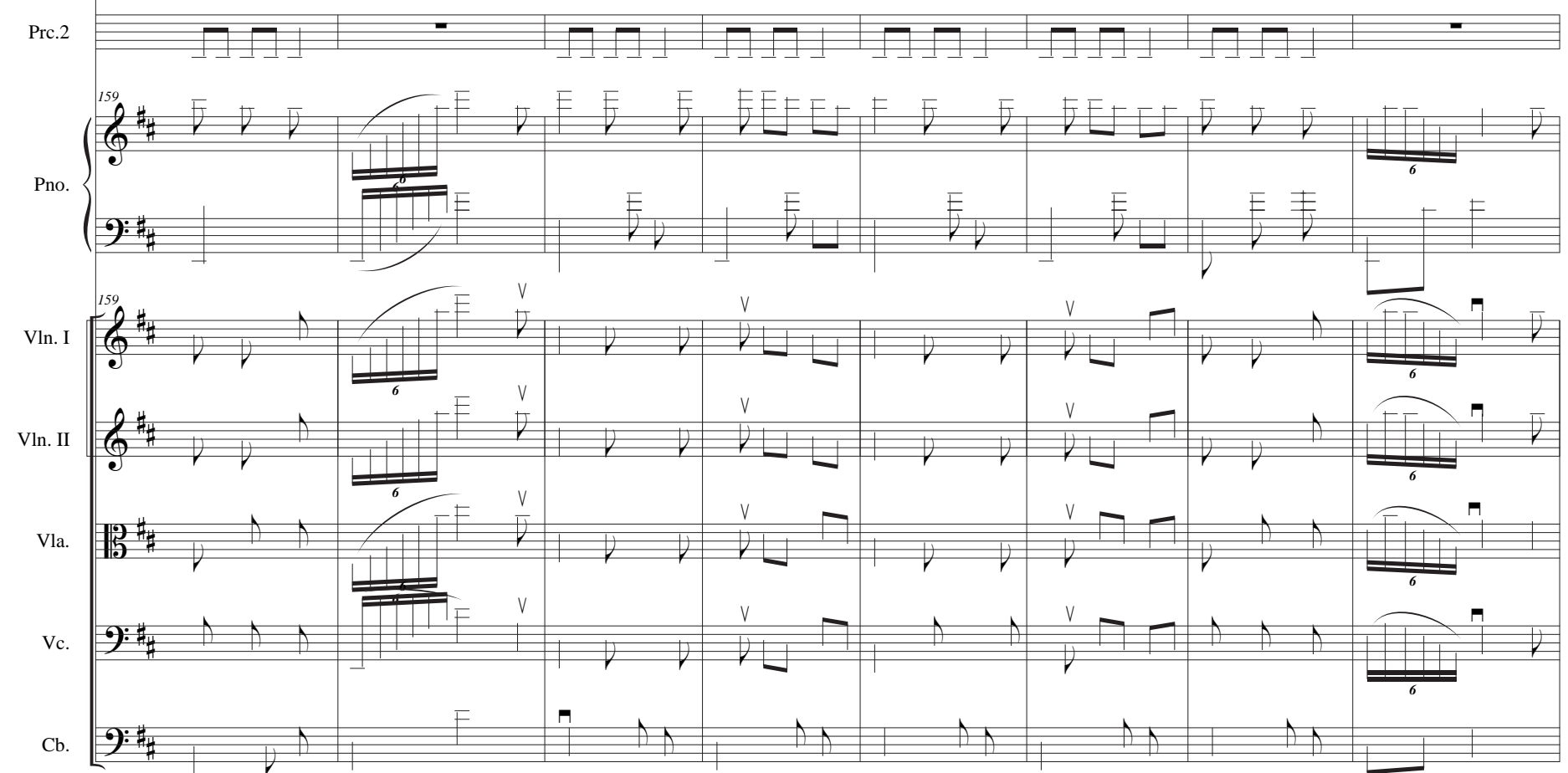

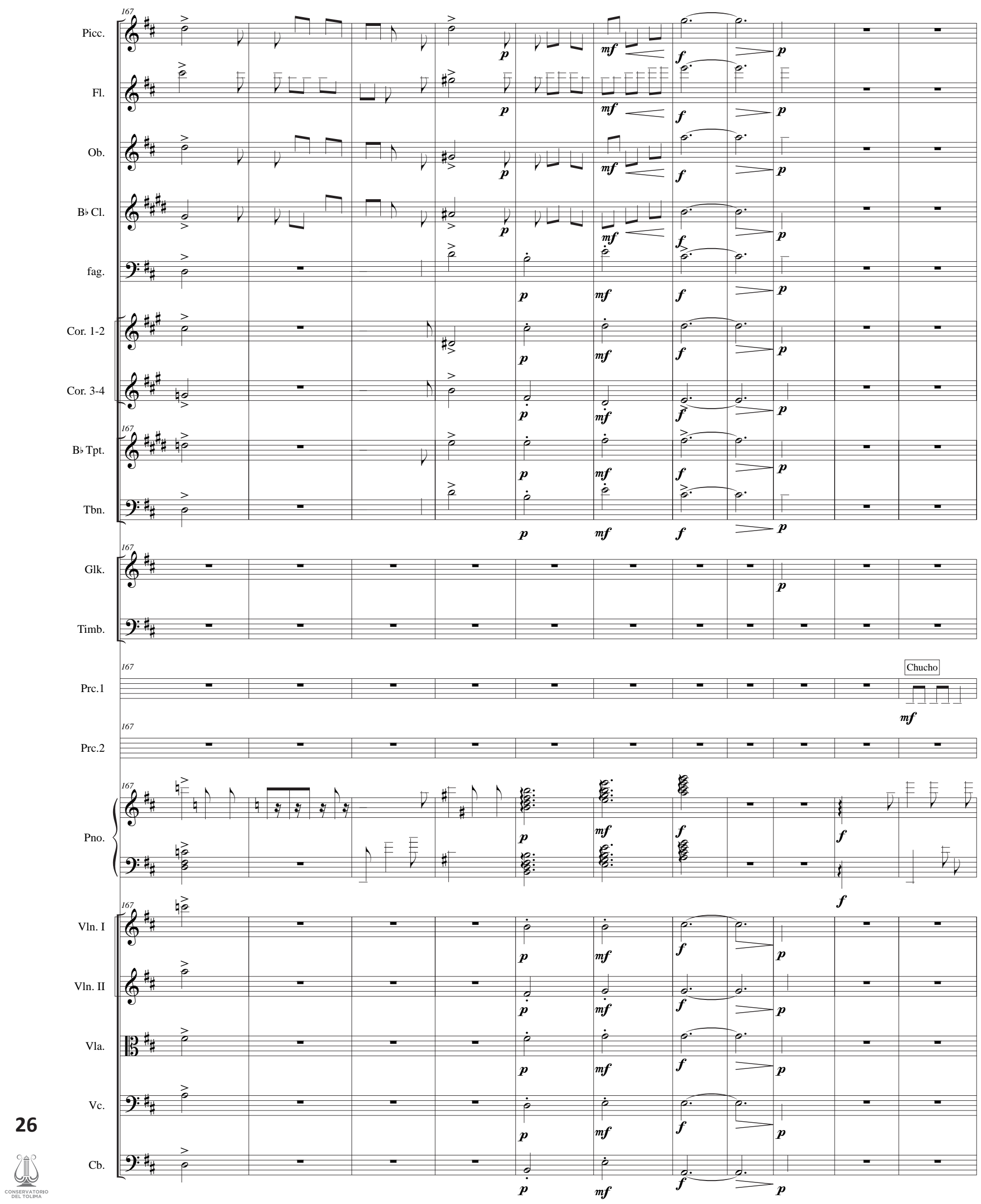

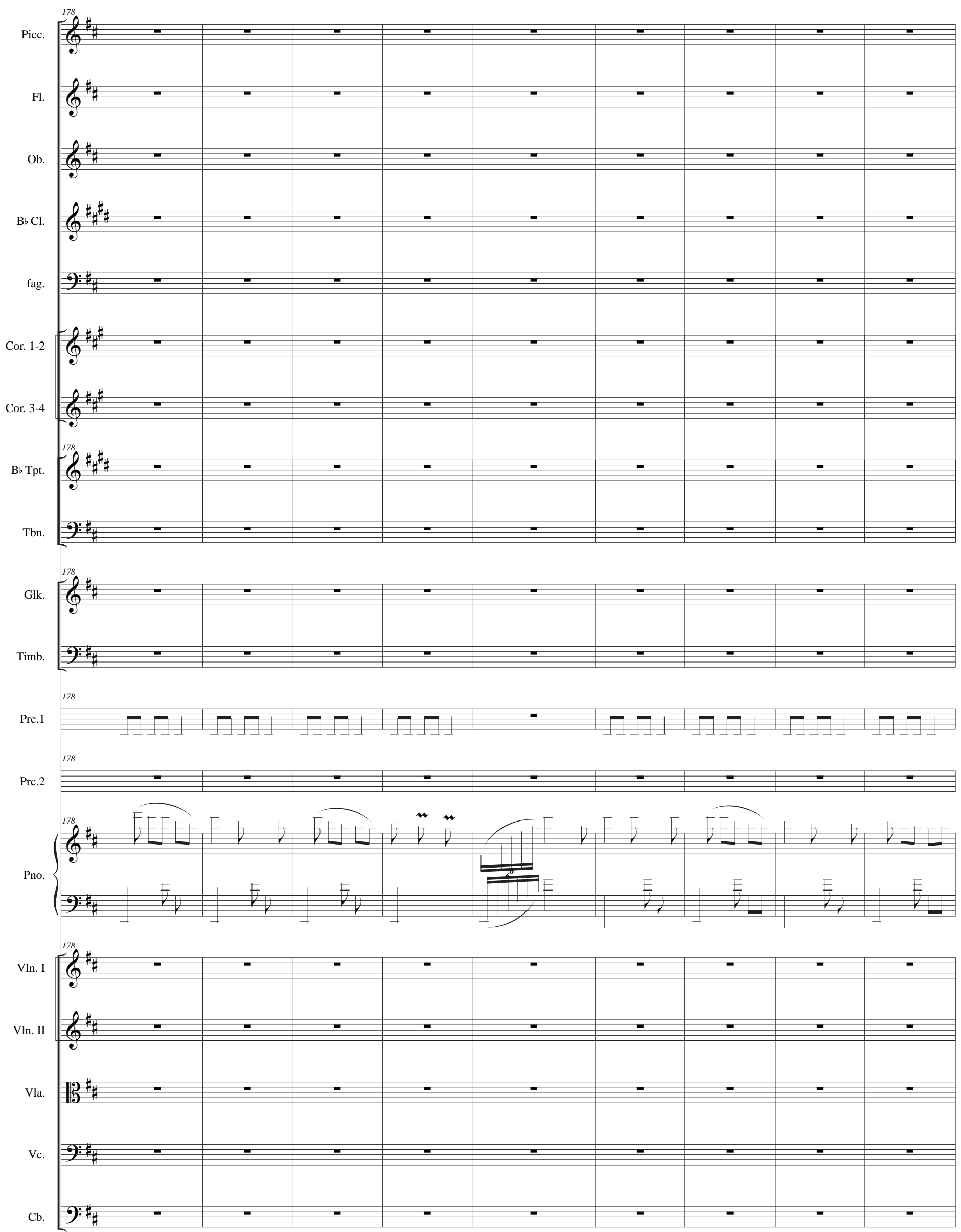

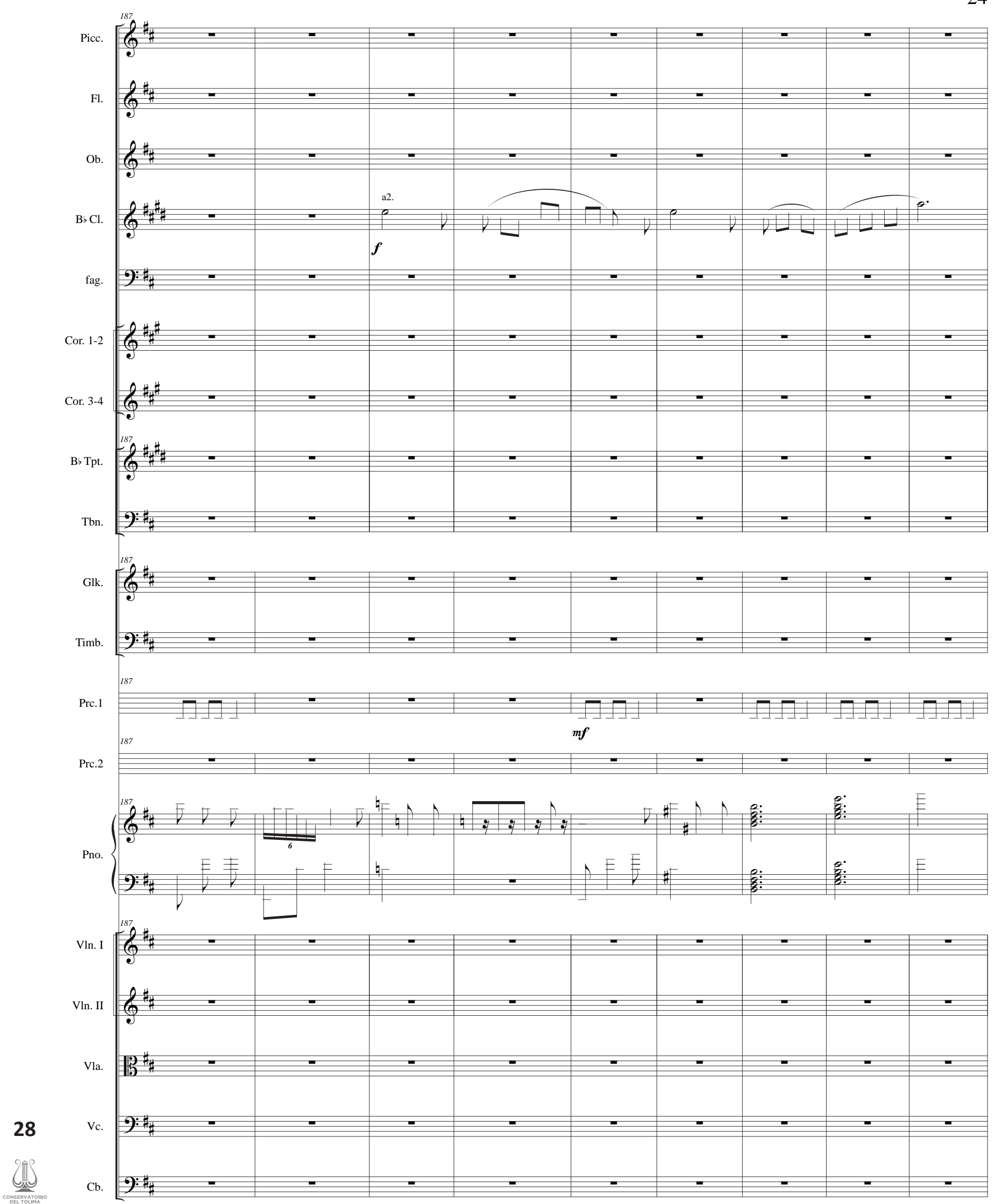

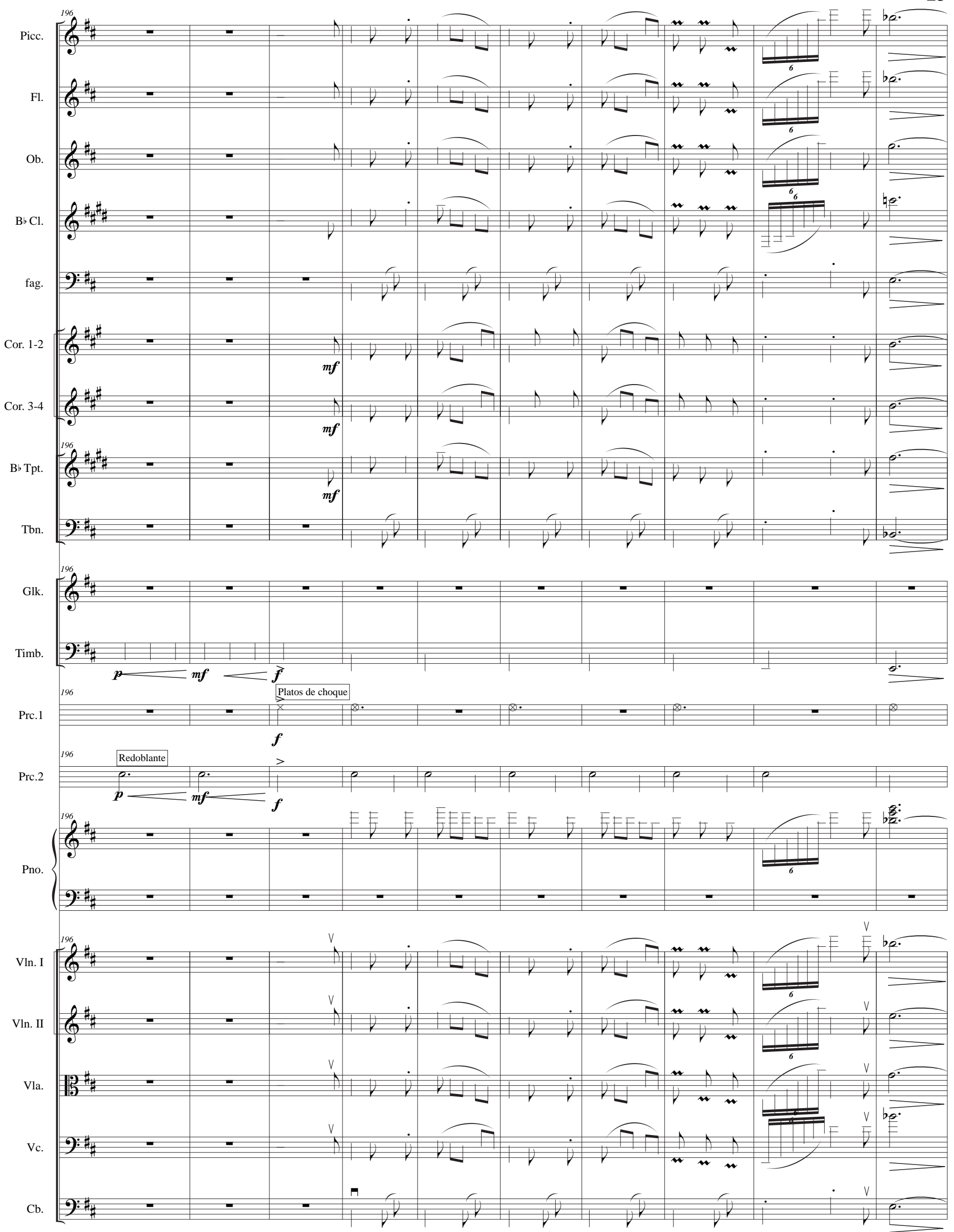

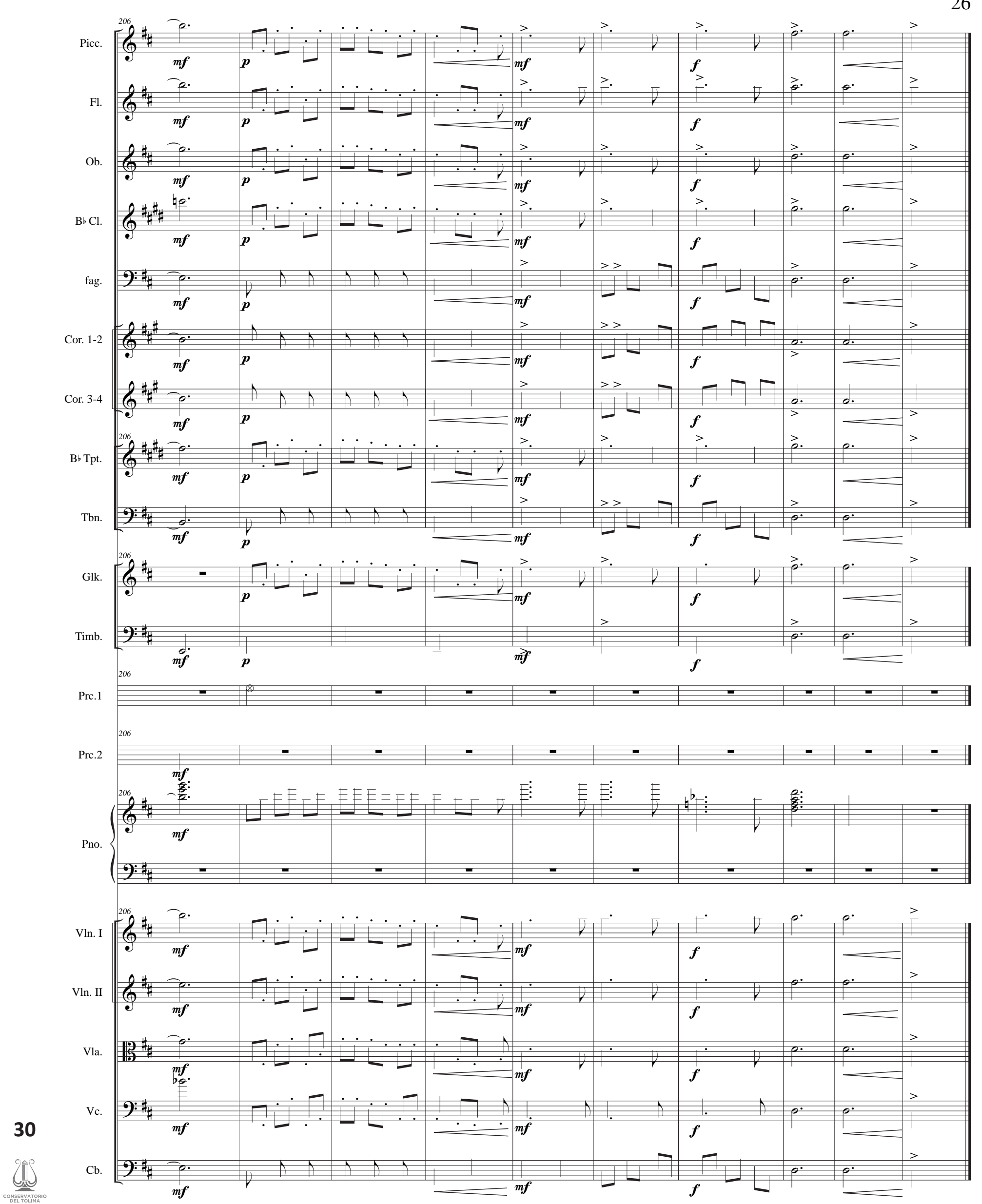


\section{Maruja Hinestrosa (1914 -2002)}

María de la Cruz Hinestrosa Eraso conocida como "Maruja Hinestrosa" nació el 16 de Noviembre en el año de 1914 en la ciudad de Pasto (Nariño) y murió a la edad de 87 años el 09 de enero del 2002. Compositora y pianista reconocida por su precocidad creadora, realiza su primer trabajo de meritada calidad a la edad de 14 años, obra insignia del movimiento cafetero en Colombia, titulada "El Cafetero".

Hija menor del matrimonio Hinestrosa Heraso; su ambiente siempre fue bajo la batuta del arte, ya que sus padres Roberto Hinestrosa y Julia Heraso, eran personajes influyentes en la sociedad cultural de la región pastusa. Él, además de ser un distinguido abogado, era un virtuoso en los instrumentos de cuerda como el tiple, el requinto y la guitarra. Ella, una magistral educadora, cantante soprano y musicóloga. Por esta razón, se considera que el primer acercamiento musical y la vocación por la composición en la vida de Maruja, se gestó desde su hogar, ya que sus padres además de todas sus labores y reconocimientos, ejercían de manera pasiva la composición musical.

Posteriormente continua su proceso musical en el Colegio del Sagrado Corazón de Jesús y en el Liceo La Merced Mari Díaz en la ciudad de Pasto; instituciones educativas donde adelantaba sus estudios de básica primaria. Allí, dos monjas fran-

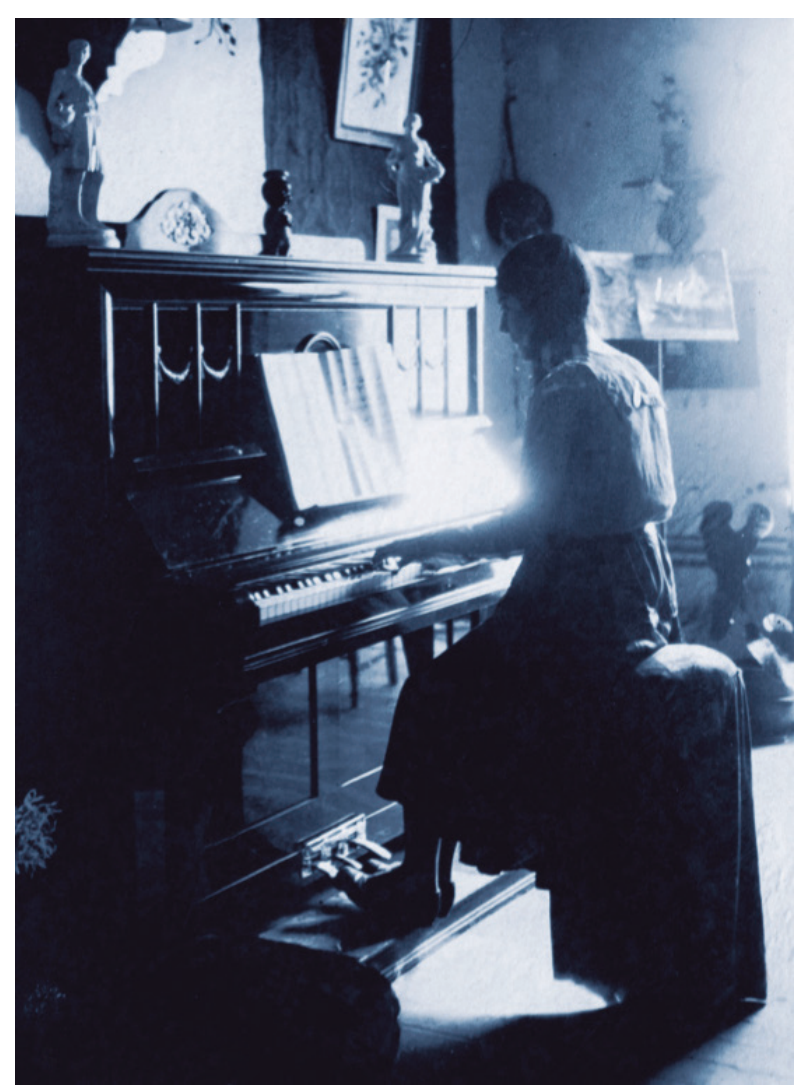

Figura 1. Maruja hinestrosa Eraso Fuente: Martínez (2014, p.18). ciscanas: Celina Pereira y la madre Bautista esta última de origen Alemán, lideraron su formación musical en teoría y técnica pianística, pero rechazando siempre la música "popular" (denominación de la compositora hacia su música), satanizando los ritmos ajenos a la práctica académica euro centrista, por tal razón, siempre que Maruja se disponía a interpretar esta música, lo hacía de manera oculta, casi como si fuera un pecado. Según Pazos Moncayo, referenciado en el libro: "Maruja Hinestrosa, La identidad nariñense a través de su piano", "la formación técnica de quienes seguían estudios de piano bajo modelos pedagógicos europeos en aquel entonces se fundamentaba principalmente en materiales como $\mathrm{EI}$ pianista virtuoso, colección de sesenta ejercicios propuestos por el francés Charles-Louis Hanon" fragmento retomado de (Martínez, 2014, pág. 26). Al igual que el método pianístico de Carl Czerny pedagogo austriaco, fueron el fundamento de la técnica pianística de Maruja Hinestrosa.

En el año de 1937, La compositora es llevada al altar por el conocido Dr. Jorge Rosero Rivera, un prestigioso ingeniero electricista de la época, que dentro de sus logros de proceso industrial en su región, se destaca por la inauguración de la primera emisora del Departamento, "Radio Nariño". Con un hogar ya establecido, llegan para completar esta familia de promotores de la ciencia y la cultura, sus tres hijos: Roberto Rosero Hinestrosa que siguió los pasos de su padre y los mellizos Jaime y Gloria Rosero Hinestrosa, él contador y ella una reconocida pintora de acuarelas. Ya en los años 30 y 40, la canción popular cobra fuerza en la radio difusión de Pasto al punto de volverse tendencia. Sencillo y magistral resultaba escuchar la 
vasta obra de la compositora, recopilada en casi un centenar de piezas que incluyen bambucos, pasilllos, boleros, tangos, valses, fantasías, y aires internacionales y latinoamericanos como cueca, son cubano, sanjuanito, y jota española.

\section{Bibliografía}

Castro, J. A., Chungana, A. S. y Gómez, A. F. (2017). Or- questación para formato sinfónico de las obras: "Fantasía sobre aires colombianos", "La flor de la montaña", "Las tres de la mañana", de Maruja Hinestrosa. Monografía. Ibagué: Conservato- rio del Tolima.

Carse, A. (1964). The history of orchestration. New York: Dover.

Georgiou, C. A. (2012). Perspectives of music publishing in the twenty-first century: The death of the editor? Hellenic Journal of Music Education, and Culture.

Korsakov, N. R. (1946). Principios de orquestación. Buenos Aires: Ricordi Americana.

Major Orchestra Librarian's Association MOLA. (1993). Guía para la preparación de música

Martínez, L. G. (2014). Maruja Hinestrosa: La identidad nariñense a través de su piano . Pasto : Panamericana Ltda.

Mejía, M. S. y Gutiérrez, D. G. (2007). Presencia y es- cencia de la mujer en la música. Santander (1900-1970). Artes y Literatura

Monroy, M. L. (s.f). La Educación Musical de la Mujer en Bogotá de 1880 a 1920. Popayán: Universidad del Cauca 


\section{NOTAS}




\section{NOTAS}




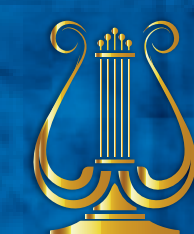

CONSERVATORIO

DEL TOLIMA

INSTITUCIÓN DE EDUCACIÓN SUPERIOR

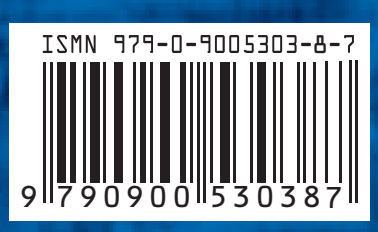

